\title{
Oncolytic Viruses as Nanomedicines against the Tumor Microenvironment
}

\author{
Uzma Zaheer $^{1,+(D)}$, Neeraja A. Hassain ${ }^{2, \dagger}$ (D), Shabeena Banu ${ }^{2}$, Shilu Mathew ${ }^{3, *(D)}$ \\ Tata Translational Cancer Research Centre, TMC Kolkata, India; Uzamzaheer786@ gmail.com (U.Z.); \\ 2 Dept. of Biotechnology, Jamal Mohamed College, Tamil Nadu, India; neeraja.anandamyle@ gmail.com (N.A.H.), \\ shanu.aura@gmail.com (S.B.); \\ 3 Biomedical Research Center, Qatar University, Qatar; shylu.ibt@gmail.com (S.M.); \\ $\dagger$ Mutual first author \\ * Correspondence: shylu.ibt@gmail.com (S.M.);
}

Scopus Author ID 56229534500

Received: 1.02.2021; Revised: 10.03.2021; Accepted: 14.03.2021; Published: 1.04.2021

\begin{abstract}
The tumor microenvironment is best described as the battleground for fighting cancer and the host immune system. Contrary to primitive beliefs that cancer growth and progression are solely dependent on cancer cells, recent studies suggest that the cancer cell mass environs also play a pivotal role. Active crosstalk between the tumor cells and their surrounding microenvironment permits their collusion to effectuate high cancer cell proliferation and metastasis. Tumors have been reported to actively recruit and alter immune cells' phenotypes and functions to either promote immune suppression or increase the tolerance towards tumor-associated antigens. Comprehending the part played by the tumor microenvironment in tumor progression and its mechanism of action paves the way for developing novel therapeutic approaches for a more personalized and efficient tumor microenvironment targeted anticancer treatment. This review elaborates on the nature and importance of the tumor microenvironment and the anti-cancer therapeutic strategies designed to target them. Furthermore, we discuss in-depth the employment of oncolytic viruses as nanomedicines for tumor microenvironment targeted anticancer therapy. This review also delineates the benefits of combining novel therapeutic approaches to existing treatment strategies to improve disease prognosis.
\end{abstract}

Keywords: tumor microenvironment; nanomedicines; oncolytic virus; nanoparticles; virotherapy.

(C) 2021 by the authors. This article is an open-access article distributed under the terms and conditions of the Creative Commons Attribution (CC BY) license (https://creativecommons.org/licenses/by/4.0/).

\section{Introduction - The Tumor Microenvironment}

Initially, cancer development was believed to be a complex process involving genetic and epigenetic changes attributed exclusively to cancer cells [1]. Tumors were considered masses of malignant cells of a 'rebel' organ comprised of numerous different cell types but were somehow adulterated by the transformed cells [2]. As research progressed, it became clear that tumors were more than just an insurgent cluster of cells. In addition to genetically mutated and proliferative cancer cells, certain components of tumors like an extracellular matrix, surrounding blood vessels, mixed non-malignant cell populations (as depicted in Figure 1), and other signaling molecules were identified tumor behavior was ascribed [3,4]. The interplay between the malignant and non-malignant components creates a microscopic ecosystem referred to as the Tumor Microenvironment (TME) [2,3], which develops through the tumor's evolving stages. In other words, the non-tumorous elements in the ecosystem co-evolve with the tumor cells during the process of tumorigenesis $[1,5]$. 


\section{A]}

\section{Major cells involved in the Tumor} Microenvironment

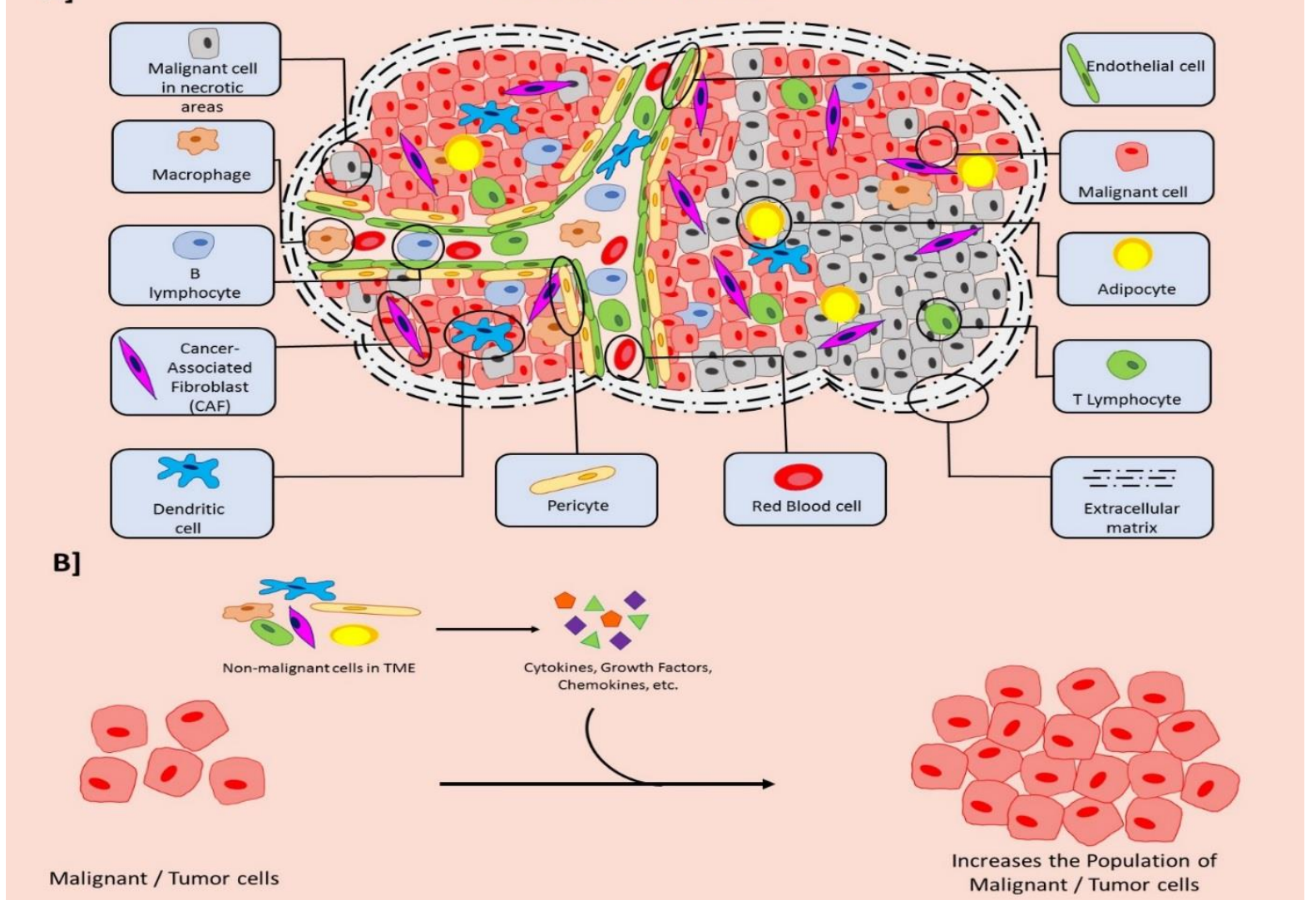

Figure 1. Graphical representation of TME with both malignant and non-malignant cells. (a) A graphical representation of the TME consisting of non-malignant cells which includes immune cells like macrophages, Blymphocytes, dendritic cells, and T-lymphocytes and pericytes, endothelial cells, red blood cells, adipocytes and CAFs, all of which are embedded in the extracellular matrix (ECM); (b) Denotes the non- malignant cell's role in tumorigenesis and thus increases the population of the existing malignant cells and the growth of the tumor.

With the aid of cell-type-specific markers, researchers paved the way for identifying the different types of non-malignant cells such as stromal cells, fibroblasts, immune cells, pericytes, and adipocytes in the TME [3]. In certain tumors, such as pancreatic ductal adenocarcinoma (PDAC), the mass and the population of stromal cells in a tumor can sometimes even outnumber the cancer cells [6]. The non-malignant cells in the TME often play a potent tumor-promoting function at all different stages of carcinogenesis [7]. The intercellular cross-talk is primarily administered by a tangled network of growth factors, chemokines, cytokines, and enzymes responsible for inflammation and matrix remodeling. Studies suggest that a healthy microenvironment is designed to protect against invasion and tumorigenesis, whereas an unhealthy microenvironment actively aids and abets the developing tumor [8]. TME is known to play a crucial role in tumor initiation and progression $[9,10]$. Metastasis of cancer is also largely dependent on the nature of the primary tumor microenvironment and the connective tissue stroma at the secondary tumor formation site, as tumor cells must interact with the endothelium at this site [11]. Evidence suggests that non-malignant components of TME reduce therapeutic efficacy by providing growth factors, antiapoptotic factors, angiogenic factors, and proteases while inhibiting the immune response for the growth, development, and spread of the tumor [4]. Hence, manipulating the TME can serve as a promising approach in treating and preventing cancer [12]. 


\section{Key Cellular Players of the TME}

\subsection{The extracellular matrix.}

The extracellular matrix (ECM) is composed of a diverse variety of proteins that provide a physical scaffold for tumors and non-malignant cells in the TME [2]. The highly dynamic ECM undergoes constant deposition, remodeling, and degradation throughout development in order to maintain tissue homeostasis. It also harbors growth factors, cytokines, and hormones released by both stromal and tumor cells [13-15] and provides chemical cues for promoting tumor development and progression [16]. During metastasis, cancer cells dissociating from the primary tumor must infiltrate and proteolytically breach the surrounding ECM. The ECM may variably serve as a barrier or facilitate the migration of these cancer cells and determine the metastasizing cells' route. The primary tumors secrete soluble factors that may prime and induce ECM remodeling of distant organs to permit engraftment of the disseminated cells [13].

\subsection{Adipose cells.}

Adipocytes supply fatty acids as fuel for the tumor cells and secrete adipokines, promoting cancer cells' progression through enhanced inflammation, cell proliferation, migration, and metastasis [17,18]. Adipocyte stem cells (ASCs) play a paramount role in tumor progression owing to their ability to differentiate into multiple cell lineages [19] and serve to promote angiogenesis through the PDGF-BB/PDGF- $\beta$ signaling pathway [20].

\subsection{Pericytes.}

Pericytes, the mesenchymal mural cells wrapped around endothelial cells spaced along the walls of venules and capillaries, are involved in maintaining vascular stability and permeability, thereby controlling the blood supply to the tumor cells [21,22]. Experimental data for a few cancers indicates that low coverage of pericytes on the vasculature often parallels poor prognosis, increased metastasis, angiogenesis, development of resistance to treatment, and higher patient mortality $[23,24]$.

\subsection{Endothelial cells.}

Endothelial cells (ECs) that form the lining of tumor blood vessels tend to differ from healthy ECs. They possess ragged margins, lack of pericyte coverage, irregular cytoplasmic projections, and leaky tight junctions, contributing to the "leakiness" of tumor vessels [25]. The tumor endothelium serves as an immune barrier to T-cell trafficking by overexpressing the endothelin B receptor, which interferes with tumor targeting of T-cell dependent immunotherapeutics. Lymphatic endothelial cells are also accountable for promoting aggressive growth of tumors and cause metastasis [26].

\subsection{Cancer-associated fibroblasts.}

Cancer-Associated Fibroblasts (CAFs) are the most abundant among the different cell populations in the TME and are accountable for the structural morphology of the ECM [27,28]. CAFs differ from the fibroblasts in healthy tissues and are known to promote tumor progression and invasion [27]. Shen et al. in 2016 reported that in lung cancer cells, FOXO3a/VEGF/ CCL2 
signaling mediated by miRNAs played a vital role in the conversion of normal fibroblasts to CAFs [29]. TGF- $\beta$ produced from the fibroblasts actuate Epithelial to Mesenchymal Transition (EMT) in tumor cells, thereby developing an immunosuppressive microenvironment [2]. CAFs produces growth factors such as Hepatocyte growth factor (HGF), Epidermal growth factor (EGF), Fibroblast growth factor (FGF), stanniocalcin-1 (STC1), and Insulin growth factor 1 (IGF1) that are either directly or indirectly involved in stimulating growth, survival, migration, and invasion [2,30,31]. CAFs secrete cytokines such as CXCL12, CXCL14, and CCL5 that have also proved to serve as pro-metastatic factors promoting tumor growth and development $[2,31]$.

\subsection{Lymphocytes.}

Cytokines such as interferon $\gamma$ (IFN- $\gamma$ ), secreted by CD8+ cytotoxic cells, promote arrest in tumor growth followed by necrosis or apoptosis in tumor cells [32]. The resulting protein components from apoptotic cells are phagocytosed by antigen-presenting cells (APCs) and presented to lymphocytes, thereby facilitating tumor suppression and indicating propitious prognosis [33,34]. On the contrary, T regulatory cells (Tregs) (i) promote immune tolerance by expressing cytokines that enhance the proliferation of CD8+ cells (ii) inhibit functions of APCs and macrophages (iii) buttress tumor progression [35,36]. Thus, the increased population of Tregs is associated with a poor prognosis [37]. Tregs also stifle effector cells' functions by the secretion of IL-10 and TGF- $\beta$ to create an immunosuppressive microenvironment [38].

Antitumor functions exhibited by B lymphocytes include cytokine production, coordination of other immune cells, granzyme B secretion-mediated direct action on tumor or, antibody-mediated indirect action [39]. B lymphocytes (APCs) are also involved in promoting tumorigenesis and tumor progression by presenting a pro-inflammatory and angiogenic microenvironment. They can directly or indirectly function in suppressing the $\mathrm{T}$ cell activation [39]. B-cells producing immunosuppressive cytokines like interleukin 10 (IL10) are termed as Bregs (B regulatory cells) or B10 cells [40]. Bregs augment tumor immune surveillance inhibition by releasing anti-inflammatory mediators (e.g., IL-10) and expressing inhibitory molecules, such as PD-L1 [41].

\subsection{Tumor-associated macrophages.}

Among the tumor-infiltrating immune cells are tumor-associated macrophages (TAMs), which can weigh half the total tumor mass in the TME and play a vital role during early carcinogenesis, tumor progression, and metastasis $[42,43]$. With the assistance of tumorderived growth factors and chemokines, monocytes derived from the bone marrow and spleen differentiate into TAMs of two subtypes: M1 and M2 [1,11]. M1, activated by IFN $\gamma$ from T helper cells (Th1), is known to produce tumoricidal effects, whereas M2, activated by Th2 released cytokines (IL-4, IL-10, and IL-13), have been observed to promote tumorigenesis [4446]. During chemotherapy, TAMs can initiate a misdirected tissue repair response that may enhance tumor growth and limited antitumor drug efficacy [47]. TAMs secrete cytokines such as IL-6, IL-1 $\beta$, IL-10, and TGF $\beta$, which can elicit T cell suppression in the TME [46]. Elevated levels of TAMs in the TME are commonly associated with poor prognosis $[48,49]$. 


\subsection{Tumor-associated neutrophils.}

The exact role and molecular associations of tumor-associated neutrophils (TANs) have not yet been clearly understood and are still widely debated [50]. Similar to M1 and M2 dichotomy, TANs in untreated tumors develop a protumorigenic (N2) phenotype, which is enhanced by the presence of TGF $\beta$ [51]. Studies reveal that neutrophils differentiating in the absence of TGF $\beta$ produced high levels of TNFa, MIP-1a, hydrogen peroxide, and nitric oxide, which prove cytotoxic to tumor cells [52]. In developed tumors, TANs secrete CCL17 or CCL22 and recruit immunosuppressive Tregs leading to suppression of antitumoral immunity $[53,54]$.

\subsection{Natural killer and natural killer T cells.}

Natural killer (NK) and natural killer T cells (NKT) are innate cytotoxic lymphocytes capable of rapidly responding to and infiltrating the tumor stroma. They are markers for a good prognosis for various cancers such as lung, colorectal, liver and, gastric cancers [55]. Crosstalk between NK-cell and macrophage produces anergic NK cells that are not cytotoxic but can enhance the killing of or differentiation of cancer stem cells (CSCs), ceasing malignant progression $[33,56]$. The exploitation of this property led to the development of NK cellmediated cancer immunotherapy, which can be augmented by immune stimulants like antibodies and cytokines [57]. NK cells may also possess chimeric antigen receptors (CARs) and extracellular vesicles (EVs) that profoundly supplement their anti-tumor activity [56].

\subsection{Dendritic cells.}

Dendritic cells are APCs capable of cross-presenting antigens to CD4+ and CD8+ T cells to induce antitumor responses against malignant cells. The maturation of dendritic cells (DC) is mainly dependent on the tumor microenvironment, and certain factors therein may influence the formation of either tolerogenic DC or immunogenic DC [58]. While immature DCs promote tumor growth through proangiogenic factors, in maturing DCs, this property is suppressed [59]. Stimulation of DCs can prove to be a promising therapeutic strategy in cancer immunotherapy since it initiates host immune response and suppresses angiogenesis $[59,60]$.

\subsection{Myeloid-derived suppressor cells.}

Various cancers show high levels of inhibitory immune cells called myeloid-derived suppressor cells (MDSCs), which are a heterogeneous mixture of cells from the myeloid lineage [61]. APC progenitors differentiate to form immature MDSCs [62]. Primarily, two essential subsets of MDSC exist, namely polymorphonuclear (PMN-MDSC) and monocytic (M-MDSC). The TME tailors the differentiation of M-MDSC to dendritic cells and macrophages. MDSCs play a crucial role in developing Tregs [63] and express arginase and nitric oxide synthase 2 that inhibit CD8+ T cell activation [64]. The functions of the various cell types in the tumor microenvironment are summarised in Table 1.

Table 1. Functions of the various cell types in the TME.

Cellular players

Tumor-Associated

Macrophages (TAMs)
Role within tumor

Involved in early carcinogenesis, tumor progression, and metastasis.

Depending on the subtype, they can either promote or interrupt

tumorigenesis. Produce angiogenic factors and accumulate in necrotic areas

of the TME.
References

$[4,11,42]$ 


\begin{tabular}{l|l|l}
\hline Cellular players & Role within tumor & References \\
\hline $\begin{array}{l}\text { Tumor-Associated } \\
\text { Neutrophils (TANs) }\end{array}$ & Possess both pro- and anti-tumor activities. & {$[65-67]$} \\
\hline $\begin{array}{l}\text { Cancer-Associated } \\
\text { Fibroblasts (CAFs) }\end{array}$ & $\begin{array}{l}\text { Produce tumor-promoting growth factors, chemokines, ECM components, } \\
\text { and ECM remodeling enzymes. It provides structural morphology for the } \\
\text { ECM. Membrane molecules play a cancer cell-supporting role. }\end{array}$ & {$[5,68]$} \\
\hline Lymphocytes & $\begin{array}{l}\text { Cytokines produced by the CD8+ cytotoxic cells are involved in the necrosis } \\
\text { and apoptosis of tumor cells. B lymphocytes can suppress T cell activation } \\
\text { and are involved in promoting tumorigenesis by the production of cytokines. }\end{array}$ & {$[32,39]$} \\
\hline $\begin{array}{l}\text { Natural Killer (Nk) } \\
\text { and Natural killer T } \\
\text { (NKT) cells }\end{array}$ & $\begin{array}{l}\text { Usually found outside the tumor area and act as markers for a good } \\
\text { prognosis. }\end{array}$ & {$[55]$} \\
\hline Dendritic cells & It might be defective and cannot stimulate an immune response. & {$[59]$} \\
\hline $\begin{array}{l}\text { Myeloid-derived } \\
\text { suppressor cells } \\
\text { (MDSCs) }\end{array}$ & $\begin{array}{l}\text { Produce large amounts of IL-10. It inhibits cytotoxic T cells and polarizes } \\
\text { TAMs to a phenotype that promotes tumors. }\end{array}$ & {$[69]$} \\
\hline Adipose cells & $\begin{array}{l}\text { Supply fatty acids as fuels for tumor cells and secretes adipokines, } \\
\text { promoting tumor cells' progression. }\end{array}$ & {$[17]$} \\
\hline Pericytes & $\begin{array}{l}\text { Provide structural support to blood vessels and maintain the vascular } \\
\text { structure, stability, permeability, and homeostasis, including blood flow and } \\
\text { ECM remodeling. }\end{array}$ & {$[22,70]$} \\
\hline $\begin{array}{l}\text { Endothelial cells } \\
\text { (ECM) }\end{array}$ & $\begin{array}{l}\text { Form a lining over tumor blood vessels that provide nutrients and oxygen } \\
\text { and provides an exit route for the metastatic cells }\end{array}$ & {$[25]$} \\
\hline $\begin{array}{l}\text { It provides a physical scaffold for all the cell types in the TME. It consists of } \\
\text { cytokines, growth factors and hormones released by stromal and tumor cells } \\
\text { that aids in promoting tumor development and progression. }\end{array}$ & {$[2]$} \\
\hline
\end{tabular}

\section{Tumor microenvironment targeted nanomedicines}

Attempts to tackle various cancers via chemotherapeutics have encountered several challenges. The tumor microenvironment has been implicated as the genesis of impediments in tumor specificity, accessibility, therapeutic efficacy, and a gradually acquired resistance to chemotherapy [71,72]. Failure of a conventional drug delivery system that is ascribed to the inimical tumor microenvironment has cued the employment of alternate strategies to target cancer cells with higher specificity and deliver drugs more efficiently. Compelling studies have indicated nanoparticles to prove efficient in tumor-targeting and drug delivery by either (i) passive targeting: diffusion of nanoparticles through leaky vessels, or (ii) active targeting: molecular recognition of tumor-specific structures via nanoparticle surface-bound ligands [73].

Tumor-microenvironment targeting of nanoparticles proved to be a promising approach to assuage this drug resistance [74]. Most strategies consider the endogenous factors and pathophysiological conditions of tumor-microenvironment such as surface charge reversal, site-specific PEG linkage detachment, reduced particle size, stimuli responsiveness to temperature and $\mathrm{pH}$, external triggers like a laser, ultrasonic waves, light or magnetic field, etc. [75]. Lee et al. exploited $\mathrm{pH}$ response to overcome DOX drug resistance in ovarian breast cancer cells. Polymeric micelles laden with DOX were comprised of two copolymers, namely poly(L-histidine)-poly (ethylene glycol) and poly(Lactic acid)-b-poly(ethylene glycol)-bpoly(L-histidine)-TAT (transactivator of transcription) such designed to guard DOX and TAT during circulation. Exposure of TAT mediated by the tumor exterior's mildly acidic $\mathrm{pH}$ allows nanoparticle internalization followed by endosomal membrane ionization and disruption releasing DOX inside the cancer cells [76]. Another intelligent drug delivery system developed by $\mathrm{Lv}$ et al. exploits the higher temperatures of tumors to facilitate the targeted release of hydrophobic 8-aniline-1-naphthalene sulfonic acid ammonium salt (ANS) drugs. The core of the nanoparticle is formed by magnetic $\mathrm{Fe}_{3} \mathrm{O}_{4}$ colloidal nanocrystal clusters (MNCs), which are linked to $\beta$-cyclodextrin ( $\beta$-CD) using poly ( $\mathrm{N}$-isopropyl acrylamide). $\beta$ - $\mathrm{CD}$ accommodate ANS and can release the same on encountering a deviation in the magnetic field and 
temperature at a rate that is dependent upon the change in temperature [77]. External triggers like a magnetic field, light, and radiation have often been used for localized activation of nanoparticles. Magnetic nanoparticles comprised of polyelectrolyte microcapsules and iron oxide nanotubes are triggered using alternating magnetic fields that heat the environment and melt microcapsule walls to release loaded drugs [78]. Light irradiation or photodynamic therapy involves the production of cytotoxic reactive singlet oxygen $\left[1 \mathrm{O}_{2}\right.$ ) from oxygen provided by oxygen self-enriched nanoparticles. In contrast, electromagnetic irradiation or photothermal therapy involves elevation of temperature via irradiation to kill cancer cells in nanoparticles' proximity.

Nanoparticles have proved to be quite promising in TME therapies, and a few clinical trials are underway. Liposomal mifamurtide, already approved in Europe, specifically targets the immune system by activating macrophages and monocytes [79]. In an ongoing phase two clinical trials (NCT03737435), Mifamurtide is an additional treatment to postoperative chemotherapy in patients with high-risk osteosarcoma. NCT00436410 and NCT00356980 are phase one clinical trials that use CYT-6091 (gold nanoparticles with TNF $\alpha$ ) that target the immune system, whereas NCT03531827 and NCT02769962 are phase 2 clinical trials that employ CRLX101, a Nanoparticle Camptothecin, in combination with Enzalutamide in patients with progressive metastatic castration-resistant Prostate Cancer and with Olaparib in patients with relapsed/refractory Small Cell Lung Cancer, respectively [80].

\section{Challenges in TME targeting of Nano-Chemotherapeutics}

Existing FDA-approved nanoparticles like Abraxane, Caelyx/Doxil, and DaunoXome, have not fared as remarkably as one may have hoped [81]. Although these nanoparticles have successfully reduced systemic toxicity, the overall survival of patients remains unimproved, suggesting that further improvement and tailoring of these nanoparticles according to the cancer type and stage and the properties of TME is required [82,83]. Combination with pretreatment strategies hyperthermia, photodynamic therapy, and radiation, as proposed by Overchuck and Zheng (2018), can improve targeting of nanoparticles tailored to the TME conditions. As the TME is highly variable, these pre-treatment strategies apply subtle changes to the TME that permit the better accumulation of these nanoformulations [84].

Initial attempts at the employment of nanoparticles exploiting the heightened permeability and retention (EPR) effect to accumulate nanoparticles in tumor tissues focused on developing stable, longer circulating nanoparticles to better localize drugs while minimizing the loss in the systemic circulation. This strategy, however, is limited by the availability of vasculature, such that highly perfused regions accumulate nano-chemotherapeutics while depriving tumors cores or hypo-perfused regions [73]. Tumor microvasculature, unlike normal blood vessels, is leaky, dilated, fragile, and often contorted. Their tortuous nature accounts for a geometrical resistance which, along with the non-laminar flow of blood, results in the discrepancy in blood distribution through tumor tissues. Concomitantly in poorly perfused regions, accessibility of immune cells or chemotherapeutics is thwarted, hypoxic and acidic conditions are exacerbated, interstitial fluid pressure is augmented [85]. To deal with this limitation, tumors must first be primed wherein either the pericyte coverage is reduced, vessel permeability or dilation is increased, or vascular perfusion and oxygenation are enhanced by anti-angiogenic drug-mediated repair of abnormal tumor vasculature [86]. 
Another issue encountered in the nano-chemotherapeutics is the impedance imposed on nanoparticles by the stiff ECM of tumor stroma post extravasation. The compressive stress exerted by the expanding collagen fibers, proliferating cancer cells, and activated CAF, along with the tensile stress experienced at the interface of normal-tumor cells countering tumor expansion, necessitate a stiff ECM where the compressive force is resisted by hyaluronan and the tensile stress is resisted by cross-linked collagen [87]. A solid tumor's stiff ECM stands as a barricade to the diffusion of nanoparticles above the size range of 20-40 nm. Furthermore, the complicated nature of the interstitial space supplements the lengths of diffusional pathways of nanoparticles. To circumvent this problem, disruption of the ECM via the use of collagenases or hyaluronidases is required, which relieves the solid stress and facilitates the better distribution of nanoparticles [88]. Even if both vascular normalization and solid stress mitigation were performed, the nanoparticle distribution is still balked by high interstitial fluid pressure. Abnormal leaky vasculature, solid stress, and malfunctioning lymphatic drainage system contribute to the building up of fluid pressure in the interstitial spaces, which tend to expel chemotherapeutics to the periphery of tumor tissue. Nanoparticles also face outward diffusion forces due to lower fluid flow in the tumor interior, leading to a loss in loaded drugs' efficacy and specificity [89]. Tumor priming agents like Apo2L/TRAIL and liposomal Imatinib have proved to lower interstitial fluid pressure significantly to improve intratumoral delivery of certain drugs $[90,91]$. However, low molecular weight nanoparticles still tended to retire to the systemic circulation via diffusion. The cumulative effect of leading to an acquired drug resistance generated a need for improved nano targeting.

\section{Role of Viruses as Nanomedicines for Cancer}

Nanoparticles can carry nanotherapeutic drugs either on their surface or internally. Drugs carried on nanoparticles' surfaces are subjected to loss during transportation in circulation and require covalent modifications. In comparison, for internalized cargo, covalent modification is not a prerequisite, and the drug is protected. Several viral vectors have been scrutinized for use in cancer therapy. The use of human adenovirus vectors has raised qualms regarding their immunogenicity and the requirement of genetic modifications. In contrast, the use of plant-based viruses minimizes toxic side effects as there is an existing tolerance by the immune system corroborated by the fact that plant viruses exist in our food chain. Studies show that these plant-based viruses possess a cargo capacity of $10 \mathrm{~nm}$. The virus-based carrier can be infused with over a thousand molecules of DOX [92]. Successful drug loading has only been demonstrated in Hibiscus chlorotic ringspot virus (HCRV) and Red clover necrotic mosaic virus (RCNMV), where the latter supports simpler and reversible loading which is dependent on calcium and magnesium ions [78,92]. The robust nature of RCNMV accounts for its tolerance to extremes of $\mathrm{pH}$ and temperature, protease and nuclease attack, and organic solvents. RCNMV has also evolved to survive in soil and mammalian circulation where $\mathrm{Ca}+2$ concentration is in the $\mathrm{mM}$ range. Its ability to sense ion concentration aids in identifying cytoplasmic conditions where the $\mathrm{Ca}^{+2}$ concentration is near the $100 \mathrm{nM}$ range. Higher concentrations of the divalent cation observed in soil result in the binding of $\mathrm{Ca}^{+2}$ to the virion surface and the consequent stabilization of the capsid. At lower concentrations, structural changes in the capsid facilitate pores' formation that causes the release of packed cargo, sometimes as big as $15 \mathrm{~nm}$ in size [92]. The calcium switch's sensitivity in RCNMV makes it a promising candidate for nano-chemotherapeutic drug delivery; however, there is no evidence of their successful replication in mammals. 
Apart from serving as delivery agents of nano-chemotherapeutics, viruses can themselves serve as nanomedicines. Virotherapy is an up-and-coming treatment plan that exploits viruses' intrinsic ability to lyse and kill their host cells. Viruses are reprogrammed to function as therapeutic agents that target and destroy diseased cells. Significant virotherapy branches include viral vector-mediated gene therapy, viral immunotherapy, and oncolytic virotherapy. Biotechnological methods like suicide gene delivery, gene knockout, and gene overexpression form the basis of these innovative treatments. The use of live viruses with the intrinsic ability to target, lyse and kill tumor cells is called Oncolytic virus therapy [93]. OV therapy is an avant-garde alternative to conventional therapies dedicated to treating various malignancies, including breast, colorectal, hepatocellular, and melanoma [94]. Observations made in the mid-1950s narrated a trend in cancer patients who were recently vaccinated or incurred a non-related viral infection to show signs of improvement [95]. Tumor necrosis factors and interferons produced in response to viral infection seemed to be at the helm. Actively proliferating cells favor the growth of all viruses. However, certain naturally occurring viruses like the parvoviruses H-1, Newcastle Disease Virus (NDV), Vesicular Stomatitis Virus (VSV), and the human reovirus prove to be oncotropic by nature. Under normal conditions, these oncolytic viruses have little to no clinical symptoms. A tumorassociated inadequacy in the interferon response pathway brings forth the oncolytic nature in these viruses [96]. This property of selectively targeting and lysing cancer cells while leaving healthy cells unscathed has led to an increased desirability of such viruses as potential therapeutic agents. Unhackneyed cancer therapy methods employing different engineered and non-engineered replication-selective oncolytic viruses are now in clinical trials [97].

\section{Oncolytic Viruses in Cancer Therapy}

Oncolytic viruses (OV) are genetically engineered viruses capable of selectively invading and replicating within cancer cells exclusively (Figure 2). Post-infection, these viruses lyse the host cells releasing thousands of copies of virions that go on to infect other cancer cells [98]. Some viruses, including picornaviruses, VSV, and vaccinia virus, which have a short life cycle and a large burst size (virus yield of each infected cell), are ideal for this purpose. The tumor tropism of viruses is effectuated by the host cells' cell surface receptors that permit viral binding to the tumor cells and allows its entry. OV viruses can recognize cell surface receptors that are specific to neoplastic cells exhibiting malignant phenotype. Polioviruses that are known to exhibit tropism for neurons recognize and bind to CD-155, which is exclusively abundant in high-grade glioma cells $[99,100]$, whereas Sindbis virus bind to high-affinity laminin receptors found to be overexpressed in several cancers [101].

On the other hand, certain viruses like vesicular stomatitis virus (VSV) bind to LDL receptors that are ubiquitously present, and thus VSVs exhibit pantropic selectivity instead of receptor specificity [102,103]. Similarly, Adenoviruses demonstrate specificity for integrins and CARs (coxsackievirus-adenovirus receptors). $\alpha v \beta 3$ and $\alpha v \beta 5$ integrins mediate the internalization of these viruses into the host cell [104]. As CARs and integrins are expressed by normal cells, Adenoviruses exhibit a broad tropism and do not possess intrinsic oncolytic properties. However, the lytic cycle of adenoviruses can be repurposed to lyse cancer cells [105] selectively. By modifying E1A and E1B genes, replicating viruses becomes restricted to cells with defective or non-functional in Rb or p53 tumor suppressor pathways, as observed in around $50 \%$ of human cancers [106]. 


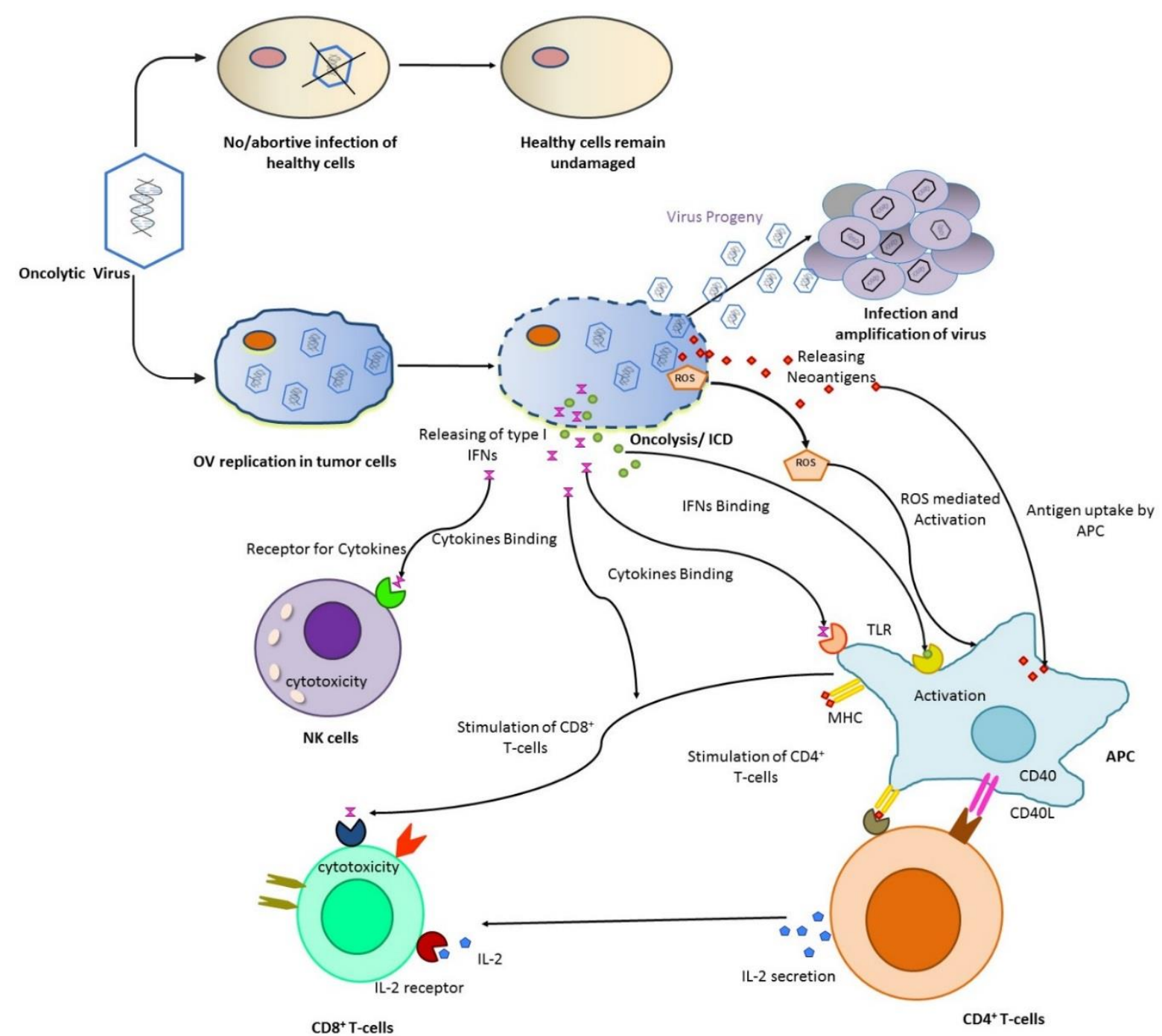

Figure 2. Dual-Mode of action of Oncolytic viruses (OVs) - Direct lysis of infected cells (oncolysis) and indirect augmentation of host antitumor immunity. Upon successful entry into the tumor cell, the virus may or may not sustain. If the cell's immune system fails to eliminate the foreign viral particle, the virus takes over the replication of the tumor cell and switches on the lytic cycle. Once the viral particles have been replicated, the tumor cell is lysed, and the virion particles are released to target further and infect surrounding tumor cells.

Oncolysis causes a release of cellular damage-associated molecular patterns (DAMPs), tumor-associated antigens (TAAs), and pathogen-associated molecular patterns (PAMPs) in a highly inflammatory process called "immunogenic cell death (ICD). These oncolytic products mediate rapid activation of a host immune response against virally infected tumor cells [107]. The oncolytic viral particles create a genotoxic and ER stress in cancer cells inducing them to secrete IFN-I, which in turn activates the NK cells and CD8 ${ }^{+} \mathrm{T}$-cells. This reaction happens to induce cytotoxicity and cell death in the nearby healthy cells. On the contrary, neoantigens are also released by the cancer cells during oncolysis, which is presented by the APC to CD4 ${ }^{+} \mathrm{T}$-cells and $\mathrm{CD} 8^{+} \mathrm{T}$-cells for activation. The activated $\mathrm{CD} 4^{+} \mathrm{T}$-cells release IL- 2 that improvise the cytotoxicity of $\mathrm{CD} 8^{+} \mathrm{T}$-cells, and thus, these mechanisms enhance immune activation against cancer cells.

Aberrantly expressed cell-cycle regulating genes like p53, p16, and retinoblastoma $(\mathrm{Rb})$, in tumor cells allow the replication and proliferation of OVs. In healthy cells, Rb regulates the cell's transition from G1 to S phase with the help of cyclin-dependent kinases and E2 transcription factor (E2F) [108]. The "guardian of the genome" or p53 is upregulated and activated in the event of DNA damage, cellular stress, or viral infection, which in turn results in activation of Bax and p21 proteins that induce apoptosis [109]. Collectively these genes function in bringing about apoptosis when the cell cycle is disrupted or dysfunctional. The disparity in the expression of cell cycle regulating proteins and mutated RAS influences the 
proliferation of cells [110]. When oncogenes are upregulated and/or tumor suppressor genes are downregulated, the cell cycle is interrupted, leading to an unbridled proliferation of cancer cells [111]. These uncontrollably proliferating cells also undergo an impaired antiviral response, allowing the survival of OVs [112]. Viruses such as adenoviruses, reoviruses, Vaccinia virus (VV), HSV-1, influenza virus, vesicular stomatitis virus (VSV), and Newcastle disease virus (NDV) capitalize on this imbalance within tumor cells and their surroundings, such as blocking of protein kinase R achieved by hyperactivation of RAS, to attain more efficient survival and replication [104]. Another suitable target for OVs like parvoviruses, reoviruses, and adenoviruses in cancer cells with mutated p53, allowing their enhanced replication.

Additionally, aberrantly expressed cell cycle proteins like $\mathrm{Rb}$ and p16 increase tumor cells' vulnerability to OVs like VV, herpes simplex virus (HSV-1), reoviruses, and adenoviruses [113]. NDVs receive a selective advantage with efficient replication in cancer cells where B-cell lymphoma-XL, an antiapoptotic protein, is upregulated [114]. The tumor microenvironment also aids in the survival and efficient replication of viruses $[115,116]$. The cells of the TME produce cytokines that affect the efficacy of successful infection by OVs. CAFs produce transforming growth factor- $\beta$ (TGF- $\beta$ ), leading to a reduction in the levels of antiviral transcripts and increases their susceptibility to OV infection. Contrarily, increased production of fibroblast growth factor 2 (FGF2) in CAFs causes reduced expression of the retinoic acid-inducible gene I (RIG-I), thereby delaying the antiviral response of cancer cells [117].

Post entry into the tumor and stromal cells of the TME, the oncolytic virus replicates and accumulates in the cytosol, progressively increasing in number and eventually leading to induction of cell lysis[118]. This lysis event releases numerous virions into the TME, where they infect other cells. However, necrosing cells also cause inflammation and recruit immune cells like dendritic cells, B and T lymphocytes. Apoptotic bodies from the necrosed cells are engulfed by Antigen-presenting cells (APCs), from which tumor-associated antigens (TAAs) are produced. APCs present these antigens to naive $\mathrm{T}$ cells through MHC complex and costimulatory molecules inducing the adaptive immune response. Necrosed cells also release danger signals, damage-associated molecular patterns (DAMPs), and pathogen-associated molecular patterns (PAMPs) that mediate activation and maturation of dendritic cells [119]. Toll-like receptors (TLRs) on sentinel cells recognize these patterns, which leads to activation of IFN-related factor (IRF) 3 and 7, RIG-I, and TNF-associated factor (TRAF) 3 in response to viral infection. These factors serve as ligands for the JAK-STAT signaling pathway resulting in increased production of interferons (INFs) involved in eliciting an antiviral response and finally inactivating the pathogen. Since this interferon-mediated signaling pathway is faulty in cancer cells, OVs can survive successfully, replicate in, and eventually lyse new tumor cells they infect. The antiviral immunity of cancer cells can be further compromised by administering certain chemotherapeutic drugs like cyclophosphamide [120]. The mechanisms of viral-induced cell death vary with different viruses. For instance, while most oncolytic adenoviruses actuate autophagic cell death, Coxsackievirus B3 (CVB3) causes immunogenic apoptosis, and oncolytic poxvirus induces necrotic/apoptotic cell death [121,122]. It is possible to skew these cell deaths into autophagic and immunogenic death pathways employing combination therapies and genetic engineering, with an incentive to sustain and fortify antitumor immunity and consequently enhance the efficacy of oncolytic immunotherapy. 
With the assistance of CD4+ and CD8+ T cells, a cytotoxic immune response is elicited post-oncolysis, which leads to the eradication of viral-infected tumor cell mass while sparing the surrounding non-infected cells [119]. Efforts are being made to buttress this immunologic "bystander" effect for non-infected cells by manipulating viruses for added therapeutic benefits. One tactic involves the viral-mediated production of single cytokines within the tumor to augment immune response and eliminate chances of systemic toxicity caused by recombinant cytokines. An apposite example would be the use of granulocyte-monocyte colony-stimulating factor (GM-CSF) known to induce specific destruction of tumor cells via CTLs directly [123]. Chemokines can also recruit a variety of cells that trigger an inflammatory response. Tumor targeting of effector T cells can be particularly enhanced by CCL5. Postinfection, oncolytic viruses are expressing CCL5 foster infiltration of dendritic cells and CD4+ lymphocytes into the tumor. The chemokine is also known to mediate increased viral persistence and engender a distinguished Th2 immune response [124]. Manipulation of the viruses, including deletion of viral genes that disrupt the IFN pathway involved with activating the innate immune response [125] and inclusion of TLR9-specific CpG rich DNA regions which bring about tumor clearance [126], are some examples of strategies used to fortify the aforementioned bystander effect.

Owing to their characteristics, various OVs have been employed in oncolytic Virotherapy. The size and type of their genomes determine the therapeutic molecules that can be inserted into these OVs and can be delivered alongside. Several viruses have been studied for their toxicity, tolerance, and efficacy and have been accordingly modified to serve as nanomedicines. In Herpes viruses, deletions in ICP34.5, a neurovirulence gene, improve cancer cells' selectivity and prevent infections in neurons [127]. Modification of Adenoviruses by inserting TGF $\beta$ receptor targeting peptide CKS17 into the hypervariable region 5 (HVR5) of the capsid protein hexon leads to decreased binding coagulation factor $\mathrm{X}$ to the virus and helps in its survival [128]. The deletion of the growth factor gene in the Vaccinia virus reduces virus virulence, whereas disruption of the vaccinia thymidine kinase (VTK) gene leads to a more selective replication in cancer cells [129].

The safety of any therapeutic agent is a reflection of its target selectivity. Increasing the tumor selectivity of OVs can be achieved using tumor-specific promoters that aid in restricting viral replication to cancerous cells while leaving the healthy tissues unscathed. Estrogen response element and Mucin-1 are viral encoded promoters in Adenoviruses that increase viral tumor selectivity in breast cancer whereas, Nestin and Musashi-1 promoters in HSV-1 increase viral tumor selectivity in brain tumors. Tropism of OVs can also be restricted to tumor cells by ablation of the virus's ability to recognize and target receptors found in normal cells. As an alternative, hexon swapping may be employed, and viruses may be pseudotyped with a more efficacious entry gene or by fusing a single-chain antibody that targets tumor-specific receptors to the entry gene [130].

Additionally, equipping recombinant oncoviruses with cytokines, $\mathrm{pH}$-releasing arms, and prodrug convertases may activate viral proteases only in the TME [131]. Prodrug convertases allow the transformation of a nontoxic metabolite or substrate into a nocuous drug. This approach permitted the inclusion of suicide and cytotoxic genes in HSV that codes for thymidine kinase, thereby induced by ganciclovir [132]. Recombinant viruses coding for decorin, relaxin, elastase, heparanase and/or hyaluronidase from macrophages metalloelastase have reportedly demonstrate TME tropism [130]. 


\subsection{In situ vaccination-induced by viral oncolysis.}

In situ tumor vaccination is an approach that brings the fight to the tumor. Herein, the synthesis of a cancer vaccine in vivo is independent of previously identified and isolated Tumor-Associated Antigens (TAA). This approach exploits TAA availability to TAA-specific adaptive immune response. Tumor cell death leads to the release of TAAs, which are subsequently processed and presented by APCs. This, in turn, cues tumor cell death instigating the release of more TAAs and subsequent presentation by APCs while simultaneously orchestrating immunomodulators. The aim of in situ vaccination to introduce a highly immunoreactive agent into an immunosuppressive tumor. The distinguishing attribute of this approach is the possibility of developing vaccines within the patients themselves such that the resource allocation requirement is minimized. To evoke a resilient anti-tumor memory immune response, a paragon in situ cancer vaccine should typically be capable of inducing immunogenic cancer cell apoptosis, facilitating the TAA release, enhancing uptake of antigen by APCs followed by their activation to effectuate tumor-directed T-cell responses that in turn engender systemic anti-tumor immunity [133-135]. Oncolytic virotherapy (OV) is progressively being recognized as a form of immunotherapy. Talimogene laherparepvec (T$\mathrm{Vec}$ ), a herpes simplex virus (HSV) encoding GM-CSF, has been licensed for clinical use in the treatment of advanced melanoma by intratumoral injection [136,137]. In situ vaccination involves the injection of only immune adjuvants into the tumor while the tumor itself contributes the antigen. Post injection, activation and expansion of effector T-cells are ensured by way of all relevant tumor antigens recognized by these T-cells. This leads to the generation of systemic antitumor immunity against tumor antigens present within the patient's tumor itself and aids in protecting them from contemporaneous or any following metastatic tumors that happen to express any common tumor antigens as found in the treated tumor [134].

\section{Delivery of Oncolytic Viruses}

Efforts are being made to improve the delivery of OVs to increase therapeutic efficacy continually. To do so, it is essential to focus on and tackle the three significant limitations to efficient delivery - (i) vascular dynamics and immune responses limiting the bioavailability of the oncovirus; (ii) hindrance caused by the TME to the propagation and biodistribution of oncovirus; (iii) amplified bystander killing effect of the virus caused by cell-to-cell contact [130]. Systemic delivery of oncolytic viruses often results in their egregious bioavailability. Intravenously administered OVs are met with rapid sequestration by the host immune system, followed by the attenuated virus's degradation [94]. Antibodies opsonize these viral particles with the help of complement proteins and other factors aiding in the recruitment of macrophages which cause phagocytosis [138,139]. Thus, clinical trials involving systemic administration of OVs have had little success [94,140,141]. Loco-regional or direct inoculation of OVs such as intrapleural administration for mesotheliomas [94], intradermal administration for melanomas [142], intracavitary administration for gliomas [143], and intraperitoneal administration for ovarian cancer [144] have also not shown promising outcomes. Despite OVs' challenges in reaching and subsequently infecting the extravascular tumor cells, direct local inoculation by intra-lesional injection in a solid tumor, and direct intravascular infusion into a significant vessel supplying the tumor, remain the main modes of administration of viral vectors [144-146]. Several clinical and preclinical studies have preferred OVs' intra-lesional administration due to the successful delivery of optimal viral load in a single dose, lower 
probability of inducing systemic toxicity, and limited viral inactivation by the innate immune system. Although the TME has several immunosuppressive mechanisms already at play, OVtreated patients demonstrated the ability to mount an antiviral immune response, leading to viral inactivation by neutralizing antibodies. Two studies involving patients suffering from Glioblastoma Multiforme (GBM) and treated with OV reported obliteration of glioma cells in xenotransplant models and in vitro. However, they failed to produce similar results in immunocompetent animals bearing tumors $[125,147,148]$. Thus, these results suggest that the immune system poses a severe obstruction to OVT. Therefore, in addition to enhancing the efficacy of the oncolytic agent employed, it's imperative to induce and maintain local immunosuppression at the administration site such that immune system-mediated viral clearance is curbed and viral persistence is prolonged.

Cyclophosphamide (CPM), an alkylating agent known to cause a reduction in vascular permeabilization, has been employed as an immunosuppressive chemotherapeutic agent in combination with OVT. Its immunosuppressive properties have also been employed in treating severe autoimmune diseases and malignancies like breast carcinomas, few types of leukemia, and (non-)Hodgkin's lymphoma. CPM pretreatment with HSV intratumoral treatment in an immunocompetent rat glioma model helped enhance the replication of the virus by causing suppression of the antiviral immune response in the injected tumors [149]. Another immunosuppressive drug that is currently used in combination with OVT is Rapamycin (Sirolimus). As a potent immunosuppressant capable of thwarting the activation and development of adaptive and innate immune responses and the production of type I IFN, Rapamycin is also employed to reduce the chances of transplant rejection. Unlike CPM, which needs to be administered in higher doses for its immunosuppressive functions and can thus often prove to be toxic, Rapamycin has been reported to be a safer clinical alternative to CPM. Valproic acid, a histone deacetylase inhibitor, is also being explored for its immunosuppressive properties. A single dose of VPA has been reported to reduce NK cells' recruitment and macrophages to the TME shortly after a viral infection; however, this effect is transient [150].

Currently, little evidence exists claiming poor dose tolerance to OV therapy or accounting reversion to virulence of inactivated viruses. However, it is vital to balance the degree of immunosuppression within the TME during oncoviral therapy. On the one hand, suppression of immune responses will aid in the intratumoral distribution of oncolytic viruses. On the other hand, enhancing the host immune responses can intensify the targeting of infected tumor cells but will simultaneously prune the intratumoral spreading of the OV [94]. Thus, OV's only mode of administration that has successfully delivered sufficient quantities of viruses while also yielding promising results is via direct or loco-regional inoculation $[94,151$ 153].

\subsection{Shielding the viral vector from the host immune system.}

Vector delivery can be made more effective by shielding the virus from the host's immune responses by either employing cell-based delivery approaches or using nanoparticle carriers as described earlier. In the case of cell-based delivery of OVs, the body's natural cells are used as a "trojan horse" to smuggle the oncoviruses to the TME. This is a passive mode of delivery in which previously infected cells in vitro serve as stealth carriers when systemically introduced into the host. As cells are the natural carriers of viruses and antiviral immune response eliciting- antigens are not expressed on these cells' surfaces until the later stages of infection, these cells carrying the oncoviruses successfully evade the host's immune defenses. 
Various cell types are being explored for this purpose, of which tumor-specific T lymphocytes and cytokine-induced killer (CIK) cells deserve special mention as they serve a dual effector/carrier purpose. Mesenchymal progenitor cells and circulating endothelial cells are also being tested for their virotherapeutic-carrier potential owing to their tumor-homing abilities. A variety of transformed and immortalized cell lineages demonstrate the ability to aid increased viral replication and release enormous OV quantities within the TME. They are hence being utilized in the delivery of oncolytic vesicular stomatitis virus, parvovirus, and measles virus in immunodeficient as well as immunocompetent animal models $[154,155]$.

The use of nanoparticle carriers to deliver OV to the tumor beds is an active form of delivery where the physical properties of these nanoparticles can be exploited to target a specific organ or tissue mass. Shielding of the viruses can be achieved by physical interface biomaterials like coating and encapsulation with polymers or biodegradable copolymers, liposomes, or nanoparticles. It may also be mediated by chemical modifications involving biomaterials like cationic polymers and lipids, arginine-grafted bioreducible polymers, poly$\mathrm{N}$-(2-hydroxypropyl) methacrylamide, bioreducible polymers, poly-L-lysine, polysaccharides, polyamidoamine, poly-ethylenimine, and polyethylene glycol (PEG) [156-158]. Immobilization of the viral vector into a biomaterial's surface through a process called substrate-mediated delivery, solid-phase delivery, or reverse transfection is yet another method to shielding the virus from the immune system. This type of shielding may account for localized expression, reduced systemic infectivity, controlled release of viruses, maintaining high local concentration, and help overcome transport-related limitations of OVT [156]. OVs' active delivery is preferable to passive delivery as the transvascular extravasation of these virotherapeutic agents is met with the same constraints as described for other nanotherapeutics, and thus immunomodulation of the tumor microenvironment is necessary.

\section{Immunomodulation at the tumor microenvironment}

Although tumor cells already have limited response to IFN stimulation and overall defective immune responses, normal cells still possess the ability to sense viral invasion even if the viral progenies are replication-deficient. Certain viruses are capable of evading or blocking the type-I IFN pathway at varied levels [155]. Wild-type oncolytic viruses have proved to be the most potent in OVT. Attenuation of the first-generation OVs is carried out to ensure therapeutic safety; however, this reduces the oncolytic potency. Hence, attempts are being made to engineer the next generation OVs by modifying molecular patterns to boost the oncolytic effect without compromising their safety effectively. Incorporation of immunestimulatory cytokine-coding genes like interleukin (IL)-18, IL-12, and IL-12 in the viral genome aids in enhanced tumor cell killing. Inhibition of angiogenesis can be mediated at the transcription level in oncolytic adenoviruses that express a short hairpin RNA that can be specific for and target VEGF or IL-8 such that angiogenesis is inhibited and tumor growth is curbed $[159,160]$. Additionally, at the transcriptional level, miRNAs encoded by recombinant OVs can be employed to safeguard it from acting on important tissues and organs that may be at high risk for severe off-target effects like in the case of coxsackievirus type A21 off-targeting results in lethal myositis [161]. Short-interfering RNA (si-RNA) can be used for posttranscriptional gene silencing due to their ability to target, bind and then cleave mRNA in a sequence homology-dependent manner in order to check toxicity and side effects and thereby increase safety [162]. At the level of translation, regulation of translation of viral protein involved in OV replication can be controlled via the internal ribosome entry site (IRES) 
element, which allows co-expression of the genes of interest from a single mRNA [163]. Survival and spread of viruses can be buttressed by the use of immunosuppressive drugs, as discussed earlier. A combination of prodrug 5-fluorocytosine with measles vaccine virus OVT brings about a pulsed immunosuppressive effect which is preferred [164].

\section{Combination Therapies Involving Oncolytic Viruses}

Combination therapy strategies can be broadly divided into three types of approaches. The first approach involving the basic combination of standard cancer therapy with an oncolytic virus carves the clinic's quickest route. Examples include: (i) the combined use of oncolytic adenovirus therapy and external beam radiotherapy (XRT) yielding more propitious results over individual standard therapies in preclinical models [165,166], (ii) engineered viruses encoding cytochrome P450 (CYP2B1) employed as an immunosuppressant and to convert CPA, a commonly used chemotherapeutic drug, to its active metabolites to limit its toxic metabolites to virus-infected cells [167] (iii) Rapamycin used to considerably enhance the oncolytic properties of poxviruses myxoma [168]. The second approach to combined therapy requires identifying barriers to oncolytic viral therapy and the development of targeted therapies to tackle these barriers. For instance, valproic acid is used to increase CAR expression in breast, bladder, and cervix cancer cells in vitro accompanied by enhanced adenoviral infection [169-171]. Lastly, the third approach utilizes the antitumor immunity developed as a byproduct of oncolysis mediated by introduced viruses and combines this with a form of immunotherapy such that a synergistic immune response is elicited against the tumor.

Though several viruses are being gauged for their potential therapeutic efficacy, only one Oncolytic herpes virus, namely Talimogene Laherparepvec, has been approved by the Food and Drug Administration (FDA) for treating melanoma [172]. Oncolytic viruses have formed an attractive therapeutic approach and are being evaluated preclinically and clinically. Examples include Adenovirus (AdV) [173], coxsackievirus [174], herpes simplex virus (HSV) [175-177], maraba virus [178,179], measles virus [180,181], Newcastle disease virus [182], parvovirus [183], reovirus [184], vaccinia virus (VACV) [185,186], and vesicular stomatitis virus (VSV) [187]. Viruses are often engineered to increase the selectivity of targeting cancer cells, abate pathogenicity towards normal cells, reduce the antiviral immune response and augment the antitumor immune response. There are two mechanisms of action through which oncolytic viruses are known to function: direct lysis of cancer cells and indirect aggrandizement of host anti-tumor immunity [188]. Either or both modes consequently improve the mode of action by genetic modification of the virus or by combination with other therapies [189]. Oncolytic Virus therapy (OVT) offers many therapeutic advantages over other existing cancer therapies such as chemotherapy and radiotherapy and may even act synergistically with these conventional approaches. OVT has a high therapeutic index when compared to other therapies. Thus, combinational therapy could potentially lead to greater therapeutic efficacy [190].

\section{Potential Future Directions for Oncolytic Virotherapy}

The eventual fate of Oncolytic Virotherapy (OVT) will concentrate on comprehension of interaction and upgrading complex collaborations between Oncolytic viruses (OVs), cancer cells, and the immune system of the host [191]. A better understanding of relationships between the malignancy type, immune status, profiles for common mutations in the tumor, and other $\mathrm{OV}$ vector species of the tumor bearer and his/her response to virotherapy will help develop 
increasingly efficacious and more customized, and personalized treatments. Investigating strategies to elevate OV access and conveyance to tumor sites by cell-based carrier systems that aim to maximize the therapeutic payload to the tumor microenvironment while simultaneously modulating the host immune system is also encouraged. Most cancer treatments employ various therapies, each with a different mechanism for tumor wreckage [192,193]. OVT is a unique but safe immunotherapy technique that may be perked up by anti-PD-1/PDL1 combined therapy. Immunosuppressive TME is known to vary from patient to patient; hence each patient's response to PD-1 blockade combination and virotherapy may differ. Execution of combination therapy in the future would benefit from the identification of various immunosuppressive pathways and the development of the enhanced tumor-infiltrating function of T-cells to potentiate OVT. Discovering biomarkers that precisely discern patients who might draw benefits from these combinations and determine which combination of therapies might prove to be most effective is of paramount importance [194]. Evidence in preclinical animal models has shown that oncolytic viruses prove meritorious in the treatment of pancreatic cancer. Observations from clinical trials (Table 2) warrant the safety and feasibility of the use of oncolytic therapies in the treatment of pancreatic cancer. Hopefully, in the future, viruses targeted to disrupt EMT may aid in curtailing the cancer stem cell population that is indicted for contributing to increased metastasis and the development of resistance to treatment. Combining systemic therapies with OVT, which aims to disrupt the desmoplastic matrix and permit better infiltration of viruses into the tumors, may show favorable results [195]. The use of virotherapy can mediate the direct lysis of tumor cells and trigger the immune system to respond against cancer. With the advent of immune checkpoint-blocking antibodies into cancer therapy, OV's immune function increasingly gains more attention than the lytic function. A phase III clinical trial for the treatment of advanced melanoma with Talimogene laherparepvec suggests that the HSV-1 based on the oncolytic viral vector could prove beneficial in combination with immune checkpoint-blocking antibodies [196]. Adenoviral vectors constructed with multiple targeting strategies having certain limitations have provided satisfactory effects in prostate cancer treatment. The combined use of multiple targeting strategies to refine adenovirus targeting is considered a prominent prospect in cancer therapy. At present, many studies with adenoviruses constructed with multiple targeting strategies such as (i) AxdAdB3-F/RGD with E1A/E1B double mutation and RGD-fiber modification, (ii) Ad5/3- $\Delta 24$-hNIS with the hybrid Ad5/3 fiber and 24-bp deletion in the E1A-CR2, and (iii) DD3-ZD55-SATB1 with the DD3 promoter and E1D-55 K deletion, have provided evidence of improved targeting and antitumor effects [197]. The mechanisms of the antitumoral function of common viral therapeutic agents combined with chemotherapeutics are yet to be understood. The viral replication mechanism inside tumor cells and the immunotherapeutic effects possibly activated by viral therapeutics are yet to be studied. An antitumor host immune response is crucial to achieving a sustained therapeutic effect. Apart from their direct antitumor effect, chemovirotherapeutics may also affect the immune system in several ways. Hence, studying the underlying mechanisms of techniques used is vital. Immunotherapeutic strategies may take a while to effectuate but are bound to be effective in patients with stable tumors. Little information exists about the extent of genotoxic chemotherapeutics mediated tumor cell death necessary to pave the way for immunotherapeutic substances to take hold in chemovirotherapeutics approaches. Therefore, these therapies' planning process must address hurdles in future experimental studies [198]. Several viruses have been identified that can potentially be engineered for use as OVs include HSV-1, HSV-2, Bovine Herpesvirus-1, 
adenovirus constructs based on serotype 5, Vesicular Stomatitis virus, vaccinia virus, and measles virus, polioviruses, modified measles virus, and parvovirus [199]. In the future, research can focus on ways in which these oncolytic viruses can be used to target and eradicate tumor cells and CSCs [200].

Table 2. List of oncolytic viruses in clinical trials against various cancers.

\begin{tabular}{|c|c|c|c|c|c|}
\hline Virus & Strain & Targeted Malignancy & $\begin{array}{l}\text { Therapy } \\
\text { Type }\end{array}$ & Phase & Reference \\
\hline \multirow[t]{9}{*}{ Vaccinia virus } & \multirow{5}{*}{$\begin{array}{l}\text { Pexastimogene } \\
\text { Devacirepvec } \\
\text { (Pexa-Vec) }\end{array}$} & Hepatocellular & Adjuvant & III & [201] \\
\hline & & $\begin{array}{l}\text { Melanoma, Lung, Renal } \\
\text { Cell, Head } \\
\text { and Neck }\end{array}$ & Primary & I & \multirow[t]{4}{*}{ [201] } \\
\hline & & Colorectal & Adjuvant & $\mathrm{I} / \mathrm{IIa}$ & \\
\hline & & Advanced Solid Tumors & Adjuvant & $\mathrm{I}$ & \\
\hline & & Blue Cell & Primary & $\mathrm{I}$ & \\
\hline & \multirow[t]{4}{*}{ GL-ONC1 } & Ovarian & Primary & I & \multirow[t]{4}{*}{ [201] } \\
\hline & & Advanced Solid Tumors & Primary & $\mathrm{I}$ & \\
\hline & & Advanced Solid Tumors & Adjuvant & $\mathrm{Ib}$ & \\
\hline & & Head and Neck & Primary & $\mathrm{I}$ & \\
\hline \multirow[t]{11}{*}{ Adenovirus } & DNX-2401 & Brain & Adjuvant & II & \multirow[t]{11}{*}{ [201] } \\
\hline & CG0070 & Bladder & Primary & II & \\
\hline & $\begin{array}{l}\text { NSC-CRAd- } \\
\text { Survivin-pk7 }\end{array}$ & Glioma & Adjuvant & I & \\
\hline & LOAd703 & Pancreatic & Adjuvant & $\mathrm{I} / \mathrm{II}$ & \\
\hline & \multirow[t]{3}{*}{$\begin{array}{l}\text { ColoAd1(Enadenotu } \\
\text { cirev) }\end{array}$} & $\begin{array}{l}\text { Colorectal, NSCLC, } \\
\text { Bladder, and Renal Cell } \\
\end{array}$ & Primary & I & \\
\hline & & Ovarian & Primary & I & \\
\hline & & $\begin{array}{l}\text { Colorectal, Bladder, and } \\
\text { Epithelial }\end{array}$ & Primary & I/II & \\
\hline & $\begin{array}{l}\text { Ad5- } \\
\text { yCD/mutTKSR39re } \\
\text { p-hIL12 }\end{array}$ & Prostate & Adjuvant & I & \\
\hline & \multirow[t]{2}{*}{ ONCOS-102 } & Melanoma & Adjuvant & I & \\
\hline & & Advanced Solid Tumors & Adjuvant & $\mathrm{I}$ & \\
\hline & $\begin{array}{l}\text { Ad5- } \\
\text { yCD/mutTKSR39re } \\
\text { p-ADP }\end{array}$ & NSCLC & Primary & I & \\
\hline $\begin{array}{l}\text { Adenovirus/Her } \\
\text { pes Simplex } \\
\text { Virus } \\
\end{array}$ & $\mathrm{ADV} / \mathrm{HSV}-\mathrm{tk}$ & Breast and NSCLC & Adjuvant & II & [201] \\
\hline \multirow[t]{8}{*}{$\begin{array}{l}\text { Herpes Simplex } \\
\text { Virus I }\end{array}$} & \multirow{3}{*}{$\begin{array}{l}\text { Talimogene } \\
\text { Laherparepvec } \\
(\mathrm{T}-\mathrm{Vec})\end{array}$} & Breast & Adjuvant & $\mathrm{I} / \mathrm{II}$ & \multirow[t]{8}{*}{ [201] } \\
\hline & & Pancreatic & Primary & $\mathrm{I}$ & \\
\hline & & Melanoma & Primary & II & \\
\hline & \multirow[t]{2}{*}{ HSV1716 } & Mesothelioma & Primary & $\mathrm{I} / \mathrm{II}$ & \\
\hline & & $\begin{array}{l}\text { Bone, Sarcomas, } \\
\text { Neuroblastomas }\end{array}$ & Primary & I & \\
\hline & \multirow[t]{2}{*}{ TBI-1401(HF10) } & Melanoma & Adjuvant & II & \\
\hline & & Superficial Solid Tumors & Primary & $\mathrm{I}$ & \\
\hline & G207 & Glioma & Primary & $\mathrm{Ib} / \mathrm{II}$ & \\
\hline \multirow[t]{6}{*}{ Reovirus } & \multirow[t]{6}{*}{ REOLYSIN } & Pancreatic & Adjuvant & $\mathrm{Ib}$ & \multirow[t]{6}{*}[201]{} \\
\hline & & Colorectal & Adjuvant & I & \\
\hline & & Multiple Myeloma & Adjuvant & I & \\
\hline & & Ovarian and Peritoneal & Adjuvant & II & \\
\hline & & Bladder & Adjuvant & $\mathrm{Ib}$ & \\
\hline & & Plasma Cell Cytoma & Adjuvant & $\mathrm{Ib}$ & \\
\hline
\end{tabular}




\begin{tabular}{|c|c|c|c|c|c|}
\hline Virus & Strain & Targeted Malignancy & $\begin{array}{l}\text { Therapy } \\
\text { Type }\end{array}$ & Phase & Reference \\
\hline \multirow[t]{6}{*}{ Measles virus } & \multirow[t]{6}{*}{ MV-NIS } & Multiple Myeloma & Adjuvant & II & \multirow[t]{6}{*}{ [201] } \\
\hline & & Ovarian & Primary & $\mathrm{I} / \mathrm{II}$ & \\
\hline & & Mesothelioma & Primary & $\mathrm{I}$ & \\
\hline & & Breast and Head and Neck & Primary & I & \\
\hline & & Nerve Sheath & Primary & I & \\
\hline & & Multiple Myeloma & Adjuvant & $\mathrm{I} / \mathrm{II}$ & \\
\hline $\begin{array}{l}\text { Vesicular } \\
\text { Stomatitis virus }\end{array}$ & $\begin{array}{l}\text { Virus VSV- } \\
\text { hIFNbeta-NIS }\end{array}$ & Endometrial & Primary & I & [201] \\
\hline \multirow[t]{2}{*}{ Coxsackievirus } & \multirow{2}{*}{ CVA21(CAVATAK } & Melanoma & Primary & II & \multirow[t]{2}{*}{ [201] } \\
\hline & & NSCLC & Adjuvant & I & \\
\hline Polio/Rhinovirus & PVSRIPO & Glioma & Primary & $\mathrm{I}$ & [201] \\
\hline Parvovirus & H-1PV(ParvOryx) & Glioblastoma Multiforme & Primary & $\mathrm{I} / \mathrm{IIa}$ & [201] \\
\hline
\end{tabular}

\section{Conclusions}

Neoteric insights in cancer biology have declared the tumor microenvironment culpable for cancer growth and metastasis. As our understanding of tumors deepened, it became clear that tumors thrive in a complex and highly heterogeneous microenvironment comprised of nonmalignant cells, including immune cells, ECM components, vasculature, CAFs, TAMs, and TANs. This review delineates the abnormal composition of the tumor microenvironment and describes strategies that target the TME to curtail cancer progression, invasion, and metastasis. Studies show that the behavior of isolated tumor cells in vitro considerably differs from when they are encompassed by a microenvironment contributing to their malignancy. This microenvironment influences the expression of surface receptors, activation or silencing of signaling pathways. It significantly sways the host's therapeutic effect or immune response. To tackle tumor resistance or no response to therapy at all and develop personalized treatment in oncology, each tumor must be regarded as a multifactorial entity that varies in each patient. This leads to the requirement of an intelligent strategy or approach regarding therapeutics, which may be a combination of existing treatments or the development of new strategies for personalized therapy. One way to achieve tailored therapy is the use of nanotherapeutics that allow tethering of different pharmacological molecules to a single nanoparticle. Another novel strategy involves the use of oncolytic viruses to target and destroy cancer cells. Their complex interactions with the immune system also allow them to be used as a vaccine for cancer. Delivery of OVs and their tumor targeting is still a problematic area for which cell-based or nanoparticle-mediated delivery approaches are being actively explored. OVs serve as fighters in the war against cancer which can be "armed" with genes of interest to improve the efficacy of OVT. OVs are also known to cause dramatic changes in the tumor microenvironment, allowing chemotherapeutics better access to cancer cells, thereby increasing their potency. Hence, having the potential to drastically improve existing therapeutic strategies when used in combination with other drugs/radiation therapies, clinical trials of oncolytic virotherapy are now underway and appear to yield promising results.

\section{Funding}

This research received no external funding. 


\section{Acknowledgments}

This research has no acknowledgment.

\section{Conflicts of Interest}

The authors declare no conflict of interest

\section{References}

1. Kim, J.; Bae, J.S. Tumor-Associated Macrophages and Neutrophils in Tumor Microenvironment. Mediators Inflamm. 2016, 2016, 6058147, https://doi.org/10.1155/2016/6058147.

2. Balkwill, F.R.; Capasso, M.; Hagemann, T. The tumor microenvironment at a glance. J. Cell Sci. 2012, 125, 5591-5596, https://doi.org/10.1242/jcs.116392.

3. Hui, L.; Chen, Y. Tumor microenvironment: Sanctuary of the devil. Cancer Lett. 2015, 368, 7-13, https://doi.org/10.1016/j.canlet.2015.07.039.

4. Leibovici, J.; Itzhaki, O.; Huszar, M.; Sinai, J. The tumor microenvironment: part 1. Immunotherapy 2011, 3, 1367-1384, https://doi.org/10.2217/imt.11.111.

5. Liu, L.; Nie, S.-P.; Xie, M. Tumor Microenvironment as a New Target for Tumor Immunotherapy of Polysaccharides. Crit. Rev. Food Sci. Nutr. 2015, 56, https://doi.org/10.1080/10408398.2015.1077191.

6. Marks, D.L.; Olson, R.L.; Fernandez-Zapico, M.E. Epigenetic control of the tumor microenvironment. Epigenomics 2016, 8, 1671-1687, https://doi.org/10.2217/epi-2016-0110.

7. Arneth, B. Tumor Microenvironment. Medicina (Kaunas) 2019, 56, https://doi.org/10.3390/medicina56010015.

8. Wang, M.; Zhao, J.; Zhang, L.; Wei, F.; Lian, Y.; Wu, Y.; Gong, Z.; Zhang, S.; Zhou, J.; Cao, K.; Li, X.; Xiong, W.; Li, G.; Zeng, Z.; Guo, C. Role of tumor microenvironment in tumorigenesis. J. Cancer 2017, 8, 761-773, https://doi.org/10.7150/jca.17648.

9. Wu, T.; Dai, Y. Tumor microenvironment and therapeutic response. Cancer Lett. 2017, 387, 61-68, https://doi.org/10.1016/j.canlet.2016.01.043.

10. DeBerardinis, R.J. Tumor Microenvironment, Metabolism, and Immunotherapy. N. Engl. J. Med. 2020, 382, 869-871, https://doi.org/10.1056/NEJMcibr1914890.

11. Abadjian, M.Z.; Edwards, W.B.; Anderson, C.J. Imaging the Tumor Microenvironment. Adv. Exp. Med. Biol. 2017, 1036, 229-257, https://doi.org/10.1007/978-3-319-67577-0_15.

12. Casey, S.C.; Amedei, A.; Aquilano, K.; Azmi, A.S.; Benencia, F.; Bhakta, D.; Bilsland, A.E.; Boosani, C.S.; Chen, S.; Ciriolo, M.R.; Crawford, S.; Fujii, H.; Georgakilas, A.G.; Guha, G.; Halicka, D.; Helferich, W.G.; Heneberg, P.; Honoki, K.; Keith, W.N.; Kerkar, S.P.; Mohammed, S.I.; Niccolai, E.; Nowsheen, S.; Vasantha Rupasinghe, H.P.; Samadi, A.; Singh, N.; Talib, W.H.; Venkateswaran, V.; Whelan, R.L.; Yang, X.; Felsher, D.W. Cancer prevention and therapy through the modulation of the tumor microenvironment. Semin. Cancer Biol. 2015, 35 Suppl, S199-S223, https://doi.org/10.1016/j.semcancer.2015.02.007.

13. Brown, E.; McKee, T.; diTomaso, E.; Pluen, A.; Seed, B.; Boucher, Y.; Jain, R.K. Dynamic imaging of collagen and its modulation in tumors in vivo using second-harmonic generation. Nat. Med. 2003, 9, 796800, https://doi.org/10.1038/nm879.

14. Wojton, J.; Kaur, B. Impact of tumor microenvironment on oncolytic viral therapy. Cytokine Growth Factor Rev. 2010, 21, 127-134, https://doi.org/10.1016/j.cytogfr.2010.02.014.

15. Monboisse, J.C.; Oudart, J.B.; Ramont, L.; Brassart-Pasco, S.; Maquart, F.X. Matrikines from basement membrane collagens: a new anti-cancer strategy. Biochim. Biophys. Acta 2014, 1840, 2589-2598, https://doi.org/10.1016/j.bbagen.2013.12.029.

16. Muenst, S.; Soysal, S.D.; Tzankov, A.; Hoeller, S. The PD-1/PD-L1 pathway: biological background and clinical relevance of an emerging treatment target in immunotherapy. Expert Opin. Ther. Targets 2015, 19, 201-211, https://doi.org/10.1517/14728222.2014.980235.

17. Nieman, K.M.; Kenny, H.A.; Penicka, C.V.; Ladanyi, A.; Buell-Gutbrod, R.; Zillhardt, M.R.; Romero, I.L.; Carey, M.S.; Mills, G.B.; Hotamisligil, G.S.; Yamada, S.D.; Peter, M.E.; Gwin, K.; Lengyel, E. Adipocytes promote ovarian cancer metastasis and provide energy for rapid tumor growth. Nat. Med. 2011, 17, 14981503, https://doi.org/10.1038/nm.2492.

18. Mertz, D.; Sentosa, J.; Luker, G.; Takayama, S. Studying Adipose Tissue in the Breast Tumor Microenvironment In Vitro: Progress and Opportunities. Tissue Eng Regen Med 2020, 17, 773-785, https://doi.org/10.1007/s13770-020-00299-9.

19. Eterno, V.; Zambelli, A.; Pavesi, L.; Villani, L.; Zanini, V.; Petrolo, G.; Manera, S.; Tuscano, A.; Amato, A. Adipose-derived Mesenchymal Stem Cells (ASCs) may favour breast cancer recurrence via HGF/c-Met signaling. Oncotarget 2014, 5, 613-633, https://doi.org/10.18632/oncotarget.1359. 
20. Amos, P.J.; Shang, H.; Bailey, A.M.; Taylor, A.; Katz, A.J.; Peirce, S.M. IFATS collection: The role of human adipose-derived stromal cells in inflammatory microvascular remodeling and evidence of a perivascular phenotype. Stem Cells 2008, 26, 2682-2690, https://doi.org/10.1634/stemcells.2008-0030.

21. Garza Treviño, E.N.; González, P.D.; Valencia Salgado, C.I.; Martinez Garza, A. Effects of pericytes and colon cancer stem cells in the tumor microenvironment. Cancer Cell Int. 2019, 19, 173, https://doi.org/10.1186/s12935-019-0888-9.

22. Armulik, A.; Genové, G.; Betsholtz, C. Pericytes: developmental, physiological, and pathological perspectives, problems, and promises. Dev. Cell 2011, 21, 193-215, https://doi.org/10.1016/j.devcel.2011.07.001.

23. Yonenaga, Y.; Mori, A.; Onodera, H.; Yasuda, S.; Oe, H.; Fujimoto, A.; Tachibana, T.; Imamura, M. Absence of smooth muscle actin-positive pericyte coverage of tumor vessels correlates with hematogenous metastasis and prognosis of colorectal cancer patients. Oncology 2005, 69, 159-166, https://doi.org/10.1159/000087840.

24. O'Keeffe, M.B.; Devlin, A.H.; Burns, A.J.; Gardiner, T.A.; Logan, I.D.; Hirst, D.G.; McKeown, S.R. Investigation of pericytes, hypoxia, and vascularity in bladder tumors: association with clinical outcomes. Oncol. Res. 2008, 17, 93-101.

25. Carmeliet, P.; Jain, R.K. Principles and mechanisms of vessel normalization for cancer and other angiogenic diseases. Nat. Rev. Drug Discov. 2011, 10, 417-427, https://doi.org/10.1038/nrd3455.

26. Swartz, M.A.; Lund, A.W. Lymphatic and interstitial flow in the tumour microenvironment: linking mechanobiology with immunity. Nat. Rev. Cancer 2012, 12, 210-219, https://doi.org/10.1038/nrc3186.

27. Kim, M.G.; Shon, Y.; Kim, J.; Oh, Y.K. Selective Activation of Anticancer Chemotherapy by CancerAssociated Fibroblasts in the Tumor Microenvironment. J. Natl. Cancer Inst. 2017, 109, https://doi.org/10.1093/jnci/djw186.

28. Bhome, R.; Bullock, M.D.; Al Saihati, H.A.; Goh, R.W.; Primrose, J.N.; Sayan, A.E.; Mirnezami, A.H. A top-down view of the tumor microenvironment: structure, cells and signaling. Front Cell Dev Biol 2015, 3, 33, https://doi.org/10.3389/fcell.2015.00033.

29. Shen, H.; Yu, X.; Yang, F.; Zhang, Z.; Shen, J.; Sun, J.; Choksi, S.; Jitkaew, S.; Shu, Y. Reprogramming of Normal Fibroblasts into Cancer-Associated Fibroblasts by miRNAs-Mediated CCL2/VEGFA Signaling. PLoS Genet. 2016, 12, e1006244, https://doi.org/10.1371/journal.pgen.1006244.

30. Calon, A.; Tauriello, D.V.; Batlle, E. TGF-beta in CAF-mediated tumor growth and metastasis. Semin. Cancer Biol. 2014, 25, 15-22, https://doi.org/10.1016/j.semcancer.2013.12.008.

31. Tao, L.; Huang, G.; Song, H.; Chen, Y.; Chen, L. Cancer associated fibroblasts: An essential role in the tumor microenvironment. Oncol. Lett. 2017, 14, 2611-2620, https://doi.org/10.3892/ol.2017.6497.

32. Matsushita, H.; Hosoi, A.; Ueha, S.; Abe, J.; Fujieda, N.; Tomura, M.; Maekawa, R.; Matsushima, K.; Ohara, O.; Kakimi, K. Cytotoxic T lymphocytes block tumor growth both by lytic activity and IFN $\gamma$-dependent cellcycle arrest. Cancer Immunol Res 2015, 3, 26-36, https://doi.org/10.1158/2326-6066.CIR-14-0098.

33. Fridman, W.H.; Pagès, F.; Sautès-Fridman, C.; Galon, J. The immune contexture in human tumours: impact on clinical outcome. Nat. Rev. Cancer 2012, 12, 298-306, https://doi.org/10.1038/nrc3245.

34. Chiang, C.L.; Balint, K.; Coukos, G.; Kandalaft, L.E. Potential approaches for more successful dendritic cellbased immunotherapy. Expert Opin. Biol. Ther. 2015, 15, 569-582, https://doi.org/10.1517/14712598.2015.1000298.

35. Facciabene, A.; Motz, G.T.; Coukos, G. T-regulatory cells: key players in tumor immune escape and angiogenesis. Cancer Res. 2012, 72, 2162-2171, https://doi.org/10.1158/0008-5472.CAN-11-3687.

36. Garris, C.S.; Luke, J.J. Dendritic Cells, the T-cell-inflamed Tumor Microenvironment, and Immunotherapy Treatment Response. Clin. Cancer. Res. 2020, 26, 3901-3907, https://doi.org/10.1158/1078-0432.ccr-191321.

37. Bohling, S.D.; Allison, K.H. Immunosuppressive regulatory T cells are associated with aggressive breast cancer phenotypes: a potential therapeutic target. Mod. Pathol. 2008, 21, 1527-1532, https://doi.org/10.1038/modpathol.2008.160.

38. Soysal, S.D.; Tzankov, A.; Muenst, S.E. Role of the Tumor Microenvironment in Breast Cancer. Pathobiology 2015, 82, 142-152, https://doi.org/10.1159/000430499.

39. Tsou, P.; Katayama, H.; Ostrin, E.J.; Hanash, S.M. The Emerging Role of B Cells in Tumor Immunity. Cancer Res. 2016, 76, 5597-5601, https://doi.org/10.1158/0008-5472.CAN-16-0431.

40. Mauri, C.; Bosma, A. Immune regulatory function of B cells. Annu. Rev. Immunol. 2012, 30, 221-241, https://doi.org/10.1146/annurev-immunol-020711-074934.

41. Schioppa, T.; Moore, R.; Thompson, R.G.; Rosser, E.C.; Kulbe, H.; Nedospasov, S.; Mauri, C.; Coussens, L.M.; Balkwill, F.R. B regulatory cells and the tumor-promoting actions of TNF- $\alpha$ during squamous carcinogenesis. Proc. Natl. Acad. Sci. U. S. A. 2011, 108, 10662-10667, https://doi.org/10.1073/pnas.1100994108.

42. Van Overmeire, E.; Laoui, D.; Keirsse, J.; Van Ginderachter, J.A.; Sarukhan, A. Mechanisms driving macrophage diversity and specialization in distinct tumor microenvironments and parallelisms with other tissues. Front. Immunol. 2014, 5, 127, https://doi.org/10.3389/fimmu.2014.00127.

43. Kelly, P.M.; Davison, R.S.; Bliss, E.; McGee, J.O. Macrophages in human breast disease: a quantitative immunohistochemical study. Br. J. Cancer 1988, 57, 174-177, https://doi.org/10.1038/bjc.1988.36. 
44. Duluc, D.; Corvaisier, M.; Blanchard, S.; Catala, L.; Descamps, P.; Gamelin, E.; Ponsoda, S.; Delneste, Y.; Hebbar, M.; Jeannin, P. Interferon-gamma reverses the immunosuppressive and protumoral properties and prevents the generation of human tumor-associated macrophages. Int. J. Cancer 2009, 125, 367-373, https://doi.org/10.1002/ijc.24401.

45. Ostuni, R.; Kratochvill, F.; Murray, P.J.; Natoli, G. Macrophages and cancer: from mechanisms to therapeutic implications. Trends Immunol. 2015, 36, 229-239, https://doi.org/10.1016/j.it.2015.02.004.

46. Qian, B.Z.; Pollard, J.W. Macrophage diversity enhances tumor progression and metastasis. Cell 2010, 141 , 39-51, https://doi.org/10.1016/j.cell.2010.03.014.

47. Mantovani, A.; Biswas, S.K.; Galdiero, M.R.; Sica, A.; Locati, M. Macrophage plasticity and polarization in tissue repair and remodelling. J. Pathol. 2013, 229, 176-185, https://doi.org/10.1002/path.4133.

48. Bingle, L.; Brown, N.J.; Lewis, C.E. The role of tumour-associated macrophages in tumour progression: implications for new anticancer therapies. J. Pathol. 2002, 196, 254-265, https://doi.org/10.1002/path.1027.

49. Vitale, I.; Manic, G.; Coussens, L.M.; Kroemer, G.; Galluzzi, L. Macrophages and Metabolism in the Tumor Microenvironment. Cell Metab. 2019, 30, 36-50, https://doi.org/10.1016/j.cmet.2019.06.001.

50. Mantovani, A.; Cassatella, M.A.; Costantini, C.; Jaillon, S. Neutrophils in the activation and regulation of innate and adaptive immunity. Nat. Rev. Immunol. 2011, 11, 519-531, https://doi.org/10.1038/nri3024.

51. Hinshaw, D.C.; Shevde, L.A. The Tumor Microenvironment Innately Modulates Cancer Progression. Cancer Res. 2019, 79, 4557-4566, https://doi.org/10.1158/0008-5472.can-18-3962.

52. Gregory, A.D.; Houghton, A.M. Tumor-associated neutrophils: new targets for cancer therapy. Cancer Res. 2011, 71, 2411-2416, https://doi.org/10.1158/0008-5472.CAN-10-2583.

53. Mishalian, I.; Bayuh, R.; Eruslanov, E.; Michaeli, J.; Levy, L.; Zolotarov, L.; Singhal, S.; Albelda, S.M.; Granot, Z.; Fridlender, Z.G. Neutrophils recruit regulatory T-cells into tumors via secretion of CCL17--a new mechanism of impaired antitumor immunity. Int. J. Cancer 2014, 135, 1178-1186, https://doi.org/10.1002/ijc.28770.

54. Jablonska, J.; Rist, M.; Lang, S.; Brandau, S. [Neutrophils in the tumor microenvironment-foes or friends?]. HNO 2020, 68, 891-898, https://doi.org/10.1007/s00106-020-00928-8.

55. Tachibana, T.; Onodera, H.; Tsuruyama, T.; Mori, A.; Nagayama, S.; Hiai, H.; Imamura, M. Increased intratumor Valpha24-positive natural killer T cells: a prognostic factor for primary colorectal carcinomas. Clin. Cancer. Res. 2005, 11, 7322-7327, https://doi.org/10.1158/1078-0432.CCR-05-0877.

56. Wilson, E.B.; El-Jawhari, J.J.; Neilson, A.L.; Hall, G.D.; Melcher, A.A.; Meade, J.L.; Cook, G.P. Human tumour immune evasion via TGF- $\beta$ blocks NK cell activation but not survival allowing therapeutic restoration of anti-tumour activity. PLoS One 2011, 6, e22842-e22842, https://doi.org/10.1371/journal.pone.0022842.

57. Baci, D.; Bosi, A.; Gallazzi, M.; Rizzi, M.; Noonan, D.M.; Poggi, A.; Bruno, A.; Mortara, L. The Ovarian Cancer Tumor Immune Microenvironment (TIME) as Target for Therapy: A Focus on Innate Immunity Cells as Therapeutic Effectors. Int. J. Mol. Sci. 2020, 21, https://doi.org/10.3390/ijms21093125.

58. Steinman, R.M.; Hawiger, D.; Nussenzweig, M.C. Tolerogenic dendritic cells. Annu. Rev. Immunol. 2003, 21, 685-711, https://doi.org/10.1146/annurev.immunol.21.120601.141040.

59. Fainaru, O.; Almog, N.; Yung, C.W.; Nakai, K.; Montoya-Zavala, M.; Abdollahi, A.; D'Amato, R.; Ingber, D.E. Tumor growth and angiogenesis are dependent on the presence of immature dendritic cells. FASEB J. 2010, 24, 1411-1418 https://doi.org/10.1096/fj.09-147025.

60. Zhu, S.; Yang, N.; Wu, J.; Wang, X.; Wang, W.; Liu, Y.J.; Chen, J. Tumor microenvironment-related dendritic cell deficiency: a target to enhance tumor immunotherapy. Pharmacol. Res. 2020, 159, 104980, https://doi.org/10.1016/j.phrs.2020.104980.

61. Gabrilovich, D.I.; Ostrand-Rosenberg, S.; Bronte, V. Coordinated regulation of myeloid cells by tumours. Nat. Rev. Immunol. 2012, 12, 253-268, https://doi.org/10.1038/nri3175.

62. Almand, B.; Clark, J.I.; Nikitina, E.; van Beynen, J.; English, N.R.; Knight, S.C.; Carbone, D.P.; Gabrilovich, D.I. Increased Production of Immature Myeloid Cells in Cancer Patients: A Mechanism of Immunosuppression in Cancer. The Journal of Immunology 2001, 166, 678, https://doi.org/10.4049/jimmunol.166.1.678.

63. Sinha, P.; Clements, V.K.; Bunt, S.K.; Albelda, S.M.; Ostrand-Rosenberg, S. Cross-Talk between MyeloidDerived Suppressor Cells and Macrophages Subverts Tumor Immunity toward a Type 2 Response. The Journal of Immunology 2007, 179, 977, https://doi.org/10.4049/jimmunol.179.2.977.

64. Bronte, V.; Serafini, P.; Mazzoni, A.; Segal, D.M.; Zanovello, P. L-arginine metabolism in myeloid cells controls T-lymphocyte functions. Trends Immunol. 2003, 24, 302-306.

65. Tsuda, Y.; Takahashi, H.; Kobayashi, M.; Hanafusa, T.; Herndon, D.N.; Suzuki, F. Three different neutrophil subsets exhibited in mice with different susceptibilities to infection by methicillin-resistant Staphylococcus aureus. Immunity 2004, 21, 215-226, https://doi.org/10.1016/j.immuni.2004.07.006.

66. Granot, Z.; Henke, E.; Comen, E.A.; King, T.A.; Norton, L.; Benezra, R. Tumor entrained neutrophils inhibit seeding in the premetastatic lung. Cancer Cell 2011, 20, 300-314, https://doi.org/10.1016/j.ccr.2011.08.012.

67. Fridlender, Z.G.; Sun, J.; Kim, S.; Kapoor, V.; Cheng, G.; Ling, L.; Worthen, G.S.; Albelda, S.M. Polarization of tumor-associated neutrophil phenotype by TGF-beta: "N1" versus "N2" TAN. Cancer Cell 2009, 16, 183194, https://doi.org/10.1016/j.ccr.2009.06.017. 
68. Li, B.; Wang, J. Fibroblasts and Myofibroblasts in Wound Healing: Force Generation and Measurement. Journal of tissue viability 2009, 20, 108-120, https://doi.org/10.1016/j.jtv.2009.11.004.

69. Kusmartsev, S.; Nefedova, Y.; Yoder, D.; Gabrilovich, D.I. Antigen-specific inhibition of CD8+ T cell response by immature myeloid cells in cancer is mediated by reactive oxygen species. J. Immunol. 2004, 172, 989-999, https://doi.org/10.4049/jimmunol.172.2.989.

70. Hosaka, K.; Yang, Y.; Seki, T.; Fischer, C.; Dubey, O.; Fredlund, E.; Hartman, J.; Religa, P.; Morikawa, H.; Ishii, Y.; Sasahara, M.; Larsson, O.; Cossu, G.; Cao, R.; Lim, S.; Cao, Y. Pericyte-fibroblast transition promotes tumor growth and metastasis. Proc. Natl. Acad. Sci. U. S. A. 2016, 113, E5618-5627, https://doi.org/10.1073/pnas.1608384113.

71. Cheng, Y.T.; Yang, C.C.; Shyur, L.F. Phytomedicine-Modulating oxidative stress and the tumor microenvironment for cancer therapy. Pharmacol. Res. 2016, 114, 128-143, https://doi.org/10.1016/j.phrs.2016.10.022.

72. Li, W.; Peng, A.; Wu, H.; Quan, Y.; Li, Y.; Lu, L.; Cui, M. Anti-Cancer Nanomedicines: A Revolution of Tumor Immunotherapy. Front. Immunol. 2020, 11, 601497, https://doi.org/10.3389/fimmu.2020.601497.

73. Stylianopoulos, T.; Munn, L.L.; Jain, R.K. Reengineering the Physical Microenvironment of Tumors to Improve Drug Delivery and Efficacy: From Mathematical Modeling to Bench to Bedside. Trends Cancer 2018, 4, 292-319, https://doi.org/10.1016/j.trecan.2018.02.005.

74. Gong, B.S.; Wang, R.; Xu, H.X.; Miao, M.Y.; Yao, Z.Z. Nanotherapy Targeting the Tumor Microenvironment. Curr. Cancer Drug Targets 2019, 19, 525-533, https://doi.org/10.2174/1568009619666181220103714.

75. Fernandes, C.; Suares, D.; Yergeri, M.C. Tumor Microenvironment Targeted Nanotherapy. Front. Pharmacol. 2018, 9, 1230, https://doi.org/10.3389/fphar.2018.01230.

76. Lee, E.S.; Gao, Z.; Kim, D.; Park, K.; Kwon, I.C.; Bae, Y.H. Super pH-sensitive multifunctional polymeric micelle for tumor $\mathrm{pH}(\mathrm{e})$ specific TAT exposure and multidrug resistance. J. Control. Release 2008, 129, 228236, https://doi.org/10.1016/j.jconrel.2008.04.024.

77. Lv, S.-N.; Cheng, C.-J.; Song, Y.-Y.; Zhao, Z.-G. Temperature-switched controlled release nanosystems based on molecular recognition and polymer phase transition. RSC Advances 2015, 5, 3248-3259, https://doi.org/10.1039/C4RA11075G.

78. Carregal-Romero, S.; Guardia, P.; Yu, X.; Hartmann, R.; Pellegrino, T.; Parak, W.J. Magnetically triggered release of molecular cargo from iron oxide nanoparticle loaded microcapsules. Nanoscale 2015, 7, 570-576, https://doi.org/10.1039/c4nr04055d.

79. Siegler, E.L.; Kim, Y.J.; Wang, P. Nanomedicine targeting the tumor microenvironment: Therapeutic strategies to inhibit angiogenesis, remodel matrix, and modulate immune responses. Journal of Cellular Immunotherapy 2016, 2, 69-78, https://doi.org/10.1016/j.jocit.2016.08.002.

80. Roma-Rodrigues, C.; Mendes, R.; Baptista, P.V.; Fernandes, A.R. Targeting Tumor Microenvironment for Cancer Therapy. Int. J. Mol. Sci. 2019, 20, 840, https://doi.org/10.3390/ijms20040840.

81. Chauhan, V.P.; Jain, R.K. Strategies for advancing cancer nanomedicine. Nature materials 2013, $12,958$.

82. Danhier, F. To exploit the tumor microenvironment: Since the EPR effect fails in the clinic, what is the future of nanomedicine? J. Controlled Release 2016, 244, 108-121, https://doi.org/10.1016/j.jconrel.2016.11.015.

83. Guo, J.; Zeng, H.; Chen, Y. Emerging Nano Drug Delivery Systems Targeting Cancer-Associated Fibroblasts for Improved Antitumor Effect and Tumor Drug Penetration. Mol. Pharm. 2020, 17, 1028-1048, https://doi.org/10.1021/acs.molpharmaceut.0c00014.

84. Overchuk, M.; Zheng, G. Overcoming obstacles in the tumor microenvironment: Recent advancements in nanoparticle delivery for cancer theranostics. Biomaterials 2018, 156, 217-237, https://doi.org/10.1016/j.biomaterials.2017.10.024.

85. Belli, C.; Trapani, D.; Viale, G.; D'Amico, P.; Duso, B.A.; Della Vigna, P.; Orsi, F.; Curigliano, G. Targeting the microenvironment in solid tumors. Cancer Treat. Rev. 2018, 65, 22-32, https://doi.org/10.1016/j.ctrv.2018.02.004.

86. Zhang, B.; Jin, K.; Jiang, T.; Wang, L.; Shen, S.; Luo, Z.; Tuo, Y.; Liu, X.; Hu, Y.; Pang, Z. Celecoxib normalizes the tumor microenvironment and enhances small nanotherapeutics delivery to A549 tumors in nude mice. Sci. Rep. 2017, 7, 10071, https://doi.org/10.1038/s41598-017-09520-7.

87. Kharaishvili, G.; Simkova, D.; Bouchalova, K.; Gachechiladze, M.; Narsia, N.; Bouchal, J. The role of cancer-associated fibroblasts, solid stress and other microenvironmental factors in tumor progression and therapy resistance. Cancer Cell Int. 2014, 14, 41, https://doi.org/10.1186/1475-2867-14-41.

88. Au, J.L.; Yeung, B.Z.; Wientjes, M.G.; Lu, Z. Delivery of cancer therapeutics to extracellular and intracellular targets: Determinants, barriers, challenges and opportunities. Adv Drug Deliv Rev 2016, 97, 280-301, https://doi.org/10.1016/j.addr.2015.12.002.

89. Nakamura, Y.; Mochida, A.; Choyke, P.L.; Kobayashi, H. Nanodrug Delivery: Is the Enhanced Permeability and Retention Effect Sufficient for Curing Cancer? Bioconjug. Chem. 2016, 27, 2225-2238, https://doi.org/10.1021/acs.bioconjchem.6b00437.

90. Fan, Y.; Du, W.; He, B.; Fu, F.; Yuan, L.; Wu, H.; Dai, W.; Zhang, H.; Wang, X.; Wang, J.; Zhang, X.; Zhang, Q. The reduction of tumor interstitial fluid pressure by liposomal imatinib and its effect on 
combination therapy with liposomal doxorubicin. Biomaterials 2013, 34, 2277-2288, https://doi.org/10.1016/j.biomaterials.2012.12.012.

91. Hylander, B.L.; Sen, A.; Beachy, S.H.; Pitoniak, R.; Ullas, S.; Gibbs, J.F.; Qiu, J.; Prey, J.D.; Fetterly, G.J.; Repasky, E.A. Tumor priming by Apo2L/TRAIL reduces interstitial fluid pressure and enhances efficacy of liposomal gemcitabine in a patient derived xenograft tumor model. Journal of controlled release : official journal of the Controlled Release Society 2015, 217, 160-169, https://doi.org/10.1016/j.jconrel.2015.08.047.

92. Loo, L.; Guenther, R.H.; Lommel, S.A.; Franzen, S. Infusion of dye molecules into Red clover necrotic mosaic virus. Chem. Commun. (Camb.) 2008, 88-90.

93. Hemminki, O.; Dos Santos, J.M.; Hemminki, A. Oncolytic viruses for cancer immunotherapy. J. Hematol. Oncol. 2020, 13, 84, https://doi.org/10.1186/s13045-020-00922-1.

94. Russell, S.J.; Peng, K.W.; Bell, J.C. Oncolytic virotherapy. Nat. Biotechnol. 2012, 30, 658-670, https://doi.org/10.1038/nbt.2287.

95. Kelly, E.; Russell, S.J. History of oncolytic viruses: genesis to genetic engineering. Mol. Ther. 2007, 15, 651659, https://doi.org/10.1038/sj.mt.6300108.

96. Jia, W.; Zhou, Q. Viral vectors for cancer gene therapy: viral dissemination and tumor targeting. Curr. Gene Ther. 2005, 5, 133-142.

97. Kirn, D.; Martuza, R.L.; Zwiebel, J. Replication-selective virotherapy for cancer: Biological principles, risk management and future directions. Nat. Med. 2001, 7, 781-787, https://doi.org/10.1038/89901.

98. Russell, L.; Peng, K.W.; Russell, S.J.; Diaz, R.M. Oncolytic Viruses: Priming Time for Cancer Immunotherapy. Biodrugs 2019, 33, 485-501, https://doi.org/10.1007/s40259-019-00367-0.

99. Merrill, M.K.; Bernhardt, G.; Sampson, J.H.; Wikstrand, C.J.; Bigner, D.D.; Gromeier, M. Poliovirus receptor CD155-targeted oncolysis of glioma. Neuro Oncol. 2004, 6, 208-217, https://doi.org/10.1215/S1152851703000577.

100.Mendelsohn, C.L.; Wimmer, E.; Racaniello, V.R. Cellular receptor for poliovirus: Molecular cloning, nucleotide sequence, and expression of a new member of the immunoglobulin superfamily. Cell 1989, 56, 855-865, https://doi.org/10.1016/0092-8674(89)90690-9.

101.Berno, V.; Porrini, D.; Castiglioni, F.; Campiglio, M.; Casalini, P.; Pupa, S.M.; Balsari, A.; Menard, S.; Tagliabue, E. The $67 \mathrm{kDa}$ laminin receptor increases tumor aggressiveness by remodeling laminin-1. Endocr. Relat. Cancer 2005, 12, 393-406.

102. Finkelshtein, D.; Werman, A.; Novick, D.; Barak, S.; Rubinstein, M. LDL receptor and its family members serve as the cellular receptors for vesicular stomatitis virus. Proc. Natl. Acad. Sci. U. S. A. 2013, 110, 73067311, https://doi.org/10.1073/pnas.1214441110.

103. Ylösmäki, E.; Cerullo, V. Design and application of oncolytic viruses for cancer immunotherapy. Curr. Opin. Biotechnol. 2020, 65, 25-36, https://doi.org/10.1016/j.copbio.2019.11.016.

104.Kaufman, H.; Kohlhapp, F.; Zloza, A. Oncolytic viruses: A new class of immunotherapy drugs. Nature reviews. Drug discovery 2015, 14, 642-662, https://doi.org/10.1038/nrd4663.

105.Kruyt, F.; Curiel, D. Toward a New Generation of Conditionally Replicating Adenoviruses: Pairing Tumor Selectivity with Maximal Oncolysis. Hum. Gene Ther. 2002, 13, 485-495, https://doi.org/10.1089/10430340252809784.

106.Fukuda, K.; Abei, M.; Ugai, H.; Seo, E.; Wakayama, M.; Murata, T.; Todoroki, T.; Tanaka, N.; Hamada, H.; Yokoyama, K. E1A, E1B double-restricted adenovirus for oncolytic gene therapy of gallbladder cancer. Cancer Res. 2003, 63, 4434-4440.

107.Davola, M.E.; Mossman, K.L. Oncolytic viruses: how "lytic" must they be for therapeutic efficacy? Oncoimmunology 2019, 8, e1581528-e1581528, https://doi.org/10.1080/2162402X.2019.1596006.

108. Harbour, J.W.; Dean, D.C. Rb function in cell-cycle regulation and apoptosis. Nat. Cell Biol. 2000, 2, E65E67, https://doi.org/10.1038/35008695.

109. Martinez, J.; Georgoff, I.; Levine, A.J. Cellular localization and cell cycle regulation by a temperaturesensitive p53 protein. Genes Dev. 1991, 5, 151-159.

110.Takai, Y.; Sasaki, T.; Matozaki, T. Small GTP-binding proteins. Physiol. Rev. 2001, 81, 153-208.

111. Collins, K.; Jacks, T.; Pavletich, N.P. The cell cycle and cancer. Proceedings of the National Academy of Sciences 1997, 94, 2776-2778.

112. Gujar, S.; Bell, J.; Diallo, J.S. SnapShot: Cancer Immunotherapy with Oncolytic Viruses. Cell 2019, 176, 1240-1240.e1241, https://doi.org/10.1016/j.cell.2019.01.051.

113.Kim, M.; Williamson, C.T.; Prudhomme, J.; Bebb, D.G.; Riabowol, K.; Lee, P.W.K.; Lees-Miller, S.P.; Mori, Y.; Rahman, M.M.; McFadden, G. The viral tropism of two distinct oncolytic viruses, reovirus and myxoma virus, is modulated by cellular tumor suppressor gene status. Oncogene 2010, 29, 3990-3996.

114. Mansour, M.; Palese, P. Oncolytic Specificity of Newcastle Disease Virus Is Mediated by Selectivity for Apoptosis-Resistant Cells. J. Virol. 2011, 85, 6015-6023, https://doi.org/10.1128/JVI.01537-10.

115.Huang, H.; Liu, Y.; Liao, W.; Cao, Y.; Liu, Q.; Guo, Y.; Lu, Y.; Xie, Z. Oncolytic adenovirus programmed by synthetic gene circuit for cancer immunotherapy. Nat Commun 2019, 10, 4801, https://doi.org/10.1038/s41467-019-12794-2. 
116.Shi, T.; Song, X.; Wang, Y.; Liu, F.; Wei, J. Combining Oncolytic Viruses With Cancer Immunotherapy: Establishing a New Generation of Cancer Treatment. Front. Immunol. 2020, 11, 683, https://doi.org/10.3389/fimmu.2020.00683.

117.Ilkow, C.S.; Marguerie, M.; Batenchuk, C.; Mayer, J.; Neriah, D.B.; Cousineau, S.; Falls, T.; Jennings, V.A.; Boileau, M.; Bellamy, D. Reciprocal cellular cross-talk within the tumor microenvironment promotes oncolytic virus activity. Nat. Med. 2015, 21, 530.

118. Harrington, K.; Freeman, D.J.; Kelly, B.; Harper, J.; Soria, J.C. Optimizing oncolytic virotherapy in cancer treatment. Nat. Rev. Drug Discov. 2019, 18, 689-706, https://doi.org/10.1038/s41573-019-0029-0.

119.Bartlett, D.L.; Liu, Z.; Sathaiah, M.; Ravindranathan, R.; Guo, Z.; He, Y.; Guo, Z.S. Oncolytic viruses as therapeutic cancer vaccines. Mol. Cancer 2013, 12, 103, https://doi.org/10.1186/1476-4598-12-103.

120.Roulstone, V.; Khan, K.; Pandha, H.S.; Rudman, S.; Coffey, M.; Gill, G.M.; Melcher, A.A.; Vile, R.; Harrington, K.J.; De Bono, J. Phase I trial of cyclophosphamide as an immune modulator for optimizing oncolytic reovirus delivery to solid tumors. Clin. Cancer. Res. 2015, 21, 1305-1312.

121.Guo, Z.S.; Naik, A.; O'Malley, M.E.; Popovic, P.; Demarco, R.; Hu, Y.; Yin, X.; Yang, S.; Zeh, H.J.; Moss, B.; Lotze, M.T.; Bartlett, D.L. The enhanced tumor selectivity of an oncolytic vaccinia lacking the host range and antiapoptosis genes SPI-1 and SPI-2. Cancer Res. 2005, 65, 9991-9998, https://doi.org/10.1158/00085472.CAN-05-1630.

122.Miyamoto, S.; Inoue, H.; Nakamura, T.; Yamada, M.; Sakamoto, C.; Urata, Y.; Okazaki, T.; Marumoto, T.; Takahashi, A.; Takayama, K.; Nakanishi, Y.; Shimizu, H.; Tani, K. Coxsackievirus B3 is an oncolytic virus with immunostimulatory properties that is active against lung adenocarcinoma. Cancer Res. 2012, 72, 26092621, https://doi.org/10.1158/0008-5472.CAN-11-3185.

123.Kim, J.H.; Oh, J.Y.; Park, B.H.; Lee, D.E.; Kim, J.S.; Park, H.E.; Roh, M.S.; Je, J.E.; Yoon, J.H.; Thorne, S.H.; Kirn, D.; Hwang, T.H. Systemic armed oncolytic and immunologic therapy for cancer with JX-594, a targeted poxvirus expressing GM-CSF. Mol. Ther. 2006, 14, 361-370, https://doi.org/10.1016/j.ymthe.2006.05.008.

124.Li, J.; O'Malley, M.; Urban, J.; Sampath, P.; Guo, Z.S.; Kalinski, P.; Thorne, S.H.; Bartlett, D.L. Chemokine expression from oncolytic vaccinia virus enhances vaccine therapies of cancer. Molecular therapy : the journal of the American Society of Gene Therapy 2011, 19, 650-657, https://doi.org/10.1038/mt.2010.312.

125.Wang, L.-C.S.; Lynn, R.C.; Cheng, G.; Alexander, E.; Kapoor, V.; Moon, E.K.; Sun, J.; Fridlender, Z.G.; Isaacs, S.N.; Thorne, S.H.; Albelda, S.M. Treating tumors with a vaccinia virus expressing IFN $\beta$ illustrates the complex relationships between oncolytic ability and immunogenicity. Molecular therapy: the journal of the American Society of Gene Therapy 2012, 20, 736-748, https://doi.org/10.1038/mt.2011.228.

126.Cerullo, V.; Diaconu, I.; Romano, V.; Hirvinen, M.; Ugolini, M.; Escutenaire, S.; Holm, S.L.; Kipar, A.; Kanerva, A.; Hemminki, A. An oncolytic adenovirus enhanced for toll-like receptor 9 stimulation increases antitumor immune responses and tumor clearance. Mol. Ther. 2012, 20, 2076-2086, https://doi.org/10.1038/mt.2012.137.

127.Poppers, J.; Mulvey, M.; Khoo, D.; Mohr, I. Inhibition of PKR activation by the proline-rich RNA binding domain of the herpes simplex virus type 1 Us11 protein. J. Virol. 2000, 74, 11215-11221.

128.Lucas, T.; Benihoud, K.; Vigant, F.; Schmidt, C.Q.A.; Bachem, M.G.; Simmet, T.; Kochanek, S. Hexon modification to improve the activity of oncolytic adenovirus vectors against neoplastic and stromal cells in pancreatic cancer. PLoS One 2015, 10.

129.Parviainen, S.; Ahonen, M.; Diaconu, I.; Kipar, A.; Siurala, M.; Vähä-Koskela, M.; Kanerva, A.; Cerullo, V.; Hemminki, A. GMCSF-armed vaccinia virus induces an antitumor immune response. Int. J. Cancer 2015, 136, 1065-1072.

130.Yokoda, R.; Nagalo, B.M.; Vernon, B.; Oklu, R.; Albadawi, H.; DeLeon, T.T.; Zhou, Y.; Egan, J.B.; Duda, D.G.; Borad, M.J. Oncolytic virus delivery: from nano-pharmacodynamics to enhanced oncolytic effect. Oncolytic virotherapy 2017, 6, 39.

131.Cattaneo, R.; Miest, T.; Shashkova, E.V.; Barry, M.A. Reprogrammed viruses as cancer therapeutics: targeted, armed and shielded. Nature Reviews Microbiology 2008, 6, 529-540.

132. Boviatsis, E.J.; Park, J.S.; Sena-Esteves, M.; Kramm, C.M.; Chase, M.; Efird, J.T.; Wei, M.X.; Breakefield, X.O.; Chiocca, E.A. Long-term survival of rats harboring brain neoplasms treated with ganciclovir and a herpes simplex virus vector that retains an intact thymidine kinase gene. Cancer Res. 1994, 54, 5745-5751.

133. Hammerich, L.; Binder, A.; Brody, J.D. In situ vaccination: Cancer immunotherapy both personalized and off-the-shelf. Mol. Oncol. 2015, 9, 1966-1981, https://doi.org/10.1016/j.molonc.2015.10.016.

134.Suresh, M.; Whitmire, J.K.; Harrington, L.E.; Larsen, C.P.; Pearson, T.C.; Altman, J.D.; Ahmed, R. Role of CD28-B7 interactions in generation and maintenance of CD8 T cell memory. J. Immunol. 2001, 167, 55655573, https://doi.org/10.4049/jimmunol.167.10.5565.

135.London, C.A.; Lodge, M.P.; Abbas, A.K. Functional responses and costimulator dependence of memory CD4+ T cells. J. Immunol. 2000, 164, 265-272, https://doi.org/10.4049/jimmunol.164.1.265.

136. Melcher, A. Abstract IA27: Oncolytic viruses: Potential for in situ anti-tumor vaccination and combination with checkpoint blockade. Cancer Immunology Research 2019, 7, IA27, https://doi.org/10.1158/23266074.CRICIMTEATIAACR18-IA27. 
137. Hamid, O.; Ismail, R.; Puzanov, I. Intratumoral Immunotherapy-Update 2019. Oncologist 2020, 25, e423e438, https://doi.org/10.1634/theoncologist.2019-0438.

138.Underhill, D.M.; Ozinsky, A. Phagocytosis of microbes: complexity in action. Annu. Rev. Immunol. 2002, 20, 825-852.

139. Osali, A.; Zhiani, M.; Ghaebi, M.; Meymanat, M.; Esmaeilzadeh, A. Multidirectional Strategies for Targeted Delivery of Oncolytic Viruses by Tumor Infiltrating Immune Cells. Pharmacol. Res. 2020, 161, 105094, https://doi.org/10.1016/j.phrs.2020.105094.

140.Fisher, K. Striking out at disseminated metastases: the systemic delivery of oncolytic viruses. Curr. Opin. Mol. Ther. 2006, 8, 301-313.

141. Seymour, L.W.; Fisher, K.D. Oncolytic viruses: finally delivering. Br. J. Cancer 2016, 114, 357-361.

142.Schreiber, R.D.; Old, L.J.; Smyth, M.J. Cancer immunoediting: integrating immunity's roles in cancer suppression and promotion. Science 2011, 331, 1565-1570.

143.Dunn, G.P.; Old, L.J.; Schreiber, R.D. The Immunobiology of Cancer Immunosurveillance and Immunoediting. Immunity 2004, 21, 137-148, https://doi.org/10.1016/j.immuni.2004.07.017.

144. Melcher, A.; Parato, K.; Rooney, C.M.; Bell, J.C. Thunder and lightning: immunotherapy and oncolytic viruses collide. Molecular therapy : the journal of the American Society of Gene Therapy 2011, 19, 10081016, https://doi.org/10.1038/mt.2011.65.

145.Shankaran, V.; Ikeda, H.; Bruce, A.T.; White, J.M.; Swanson, P.E.; Old, L.J.; Schreiber, R.D. IFN $\gamma$ and lymphocytes prevent primary tumour development and shape tumour immunogenicity. Nature 2001, 410, 1107-1111, https://doi.org/10.1038/35074122.

146. Howard, F.; Muthana, M. Designer nanocarriers for navigating the systemic delivery of oncolytic viruses. Nanomedicine (Lond) 2020, 15, 93-110, https://doi.org/10.2217/nnm-2019-0323.

147.Lun, X.; Alain, T.; Zemp, F.J.; Zhou, H.; Rahman, M.M.; Hamilton, M.G.; McFadden, G.; Bell, J.; Senger, D.L.; Forsyth, P.A. Myxoma virus virotherapy for glioma in immunocompetent animal models: optimizing administration routes and synergy with rapamycin. Cancer Res. 2010, 70, 598-608.

148.Fulci, G.; Dmitrieva, N.; Gianni, D.; Fontana, E.J.; Pan, X.; Lu, Y.; Kaufman, C.S.; Kaur, B.; Lawler, S.E.; Lee, R.J. Depletion of peripheral macrophages and brain microglia increases brain tumor titers of oncolytic viruses. Cancer Res. 2007, 67, 9398-9406.

149.Wakimoto, H.; Fulci, G.; Tyminski, E.; Chiocca, E.A. Altered expression of antiviral cytokine mRNAs associated with cyclophosphamide's enhancement of viral oncolysis. Gene Ther. 2004, 11, 214-223.

150.Koks, C.A.E.; De Vleeschouwer, S.; Graf, N.; Van Gool, S.W. Immune suppression during oncolytic virotherapy for high-grade glioma; yes or no? J. Cancer 2015, 6, 203.

151.Bommareddy, P.K.; Patel, A.; Hossain, S.; Kaufman, H.L. Talimogene laherparepvec (T-VEC) and other oncolytic viruses for the treatment of melanoma. Am. J. Clin. Dermatol. 2017, 18, 1-15.

152.Barton, K.N.; Stricker, H.; Brown, S.L.; Elshaikh, M.; Aref, I.; Lu, M.; Pegg, J.; Zhang, Y.; Karvelis, K.C.; Siddiqui, F. Phase I study of noninvasive imaging of adenovirus-mediated gene expression in the human prostate. Mol. Ther. 2008, 16, 1761-1769.

153.De Silva, N.; Atkins, H.; Kirn, D.H.; Bell, J.C.; Breitbach, C.J. Double trouble for tumours: exploiting the tumour microenvironment to enhance anticancer effect of oncolytic viruses. Cytokine Growth Factor Rev. 2010, 21, 135-141.

154.Power, A.T.; Bell, J.C. Cell-based delivery of oncolytic viruses: a new strategic alliance for a biological strike against cancer. Mol. Ther. 2007, 15, 660-665.

155.Christensen, M.H.; Paludan, S.R. Viral evasion of DNA-stimulated innate immune responses. Cell. Mol. Immunol. 2017, 14, 4-13.

156.Kim, J.; Kim, P.-H.; Kim, S.W.; Yun, C.-O. Enhancing the therapeutic efficacy of adenovirus in combination with biomaterials. Biomaterials 2012, 33, 1838-1850.

157.Duncan, R.; Vicent, M.J. Do HPMA copolymer conjugates have a future as clinically useful nanomedicines? A critical overview of current status and future opportunities. Adv. Drug Del. Rev. 2010, 62, 272-282.

158. Lammers, T. Improving the efficacy of combined modality anticancer therapy using HPMA copolymer-based nanomedicine formulations. Adv. Drug Del. Rev. 2010, 62, 203-230.

159. Yoo, J.Y.; Kim, J.H.; Kim, J.; Huang, J.H.; Zhang, S.N.; Kang, Y.A.; Kim, H.; Yun, C.O. Short hairpin RNAexpressing oncolytic adenovirus-mediated inhibition of IL-8: effects on antiangiogenesis and tumor growth inhibition. Gene Ther. 2008, 15, 635-651, https://doi.org/10.1038/gt.2008.3.

160.Yoo, J.Y.; Kim, J.-H.; Kwon, Y.-G.; Kim, E.-C.; Kim, N.K.; Choi, H.J.; Yun, C.-O. VEGF-specific Short Hairpin RNA-expressing Oncolytic Adenovirus Elicits Potent Inhibition of Angiogenesis and Tumor Growth. Mol. Ther. 2007, 15, 295-302, https://doi.org/10.1038/sj.mt.6300023.

161.Kelly, E.J.; Hadac, E.M.; Greiner, S.; Russell, S.J. Engineering microRNA responsiveness to decrease virus pathogenicity. Nat. Med. 2008, 14, 1278.

162. Kullberg, M.; McCarthy, R.; Anchordoquy, T.J. Systemic tumor-specific gene delivery. J. Controlled Release 2013, 172, 730-736.

163.Renaud-Gabardos, E.; Hantelys, F.; Morfoisse, F.; Chaufour, X.; Garmy-Susini, B.; Prats, A.-C. Internal ribosome entry site-based vectors for combined gene therapy. World journal of experimental medicine 2015, 5,11 . 
164. Yurttas, C.; Berchtold, S.; Malek, N.P.; Bitzer, M.; Lauer, U.M. Pulsed versus continuous application of the prodrug 5-fluorocytosine to enhance the oncolytic effectiveness of a measles vaccine virus armed with a suicide gene. Human gene therapy Clinical development 2014, 25, 85-96.

165.Bieler, A.; Mantwill, K.; Holzmüller, R.; Jürchott, K.; Kaszubiak, A.; Stärk, S.; Glockzin, G.; Lage, H.; Grosu, A.L.; Gansbacher, B.; Holm, P.S. Impact of radiation therapy on the oncolytic adenovirus dl520: implications on the treatment of glioblastoma. Radiother. Oncol. 2008, 86, 419-427, https://doi.org/10.1016/j.radonc.2007.10.009.

166. Geoerger, B.; Grill, J.; Opolon, P.; Morizet, J.; Aubert, G.; Lecluse, Y.; van Beusechem, V.W.; Gerritsen, W.R.; Kirn, D.H.; Vassal, G. Potentiation of radiation therapy by the oncolytic adenovirus d11520 (ONYX015) in human malignant glioma xenografts. Br. J. Cancer 2003, 89, 577-584, https://doi.org/10.1038/sj.bjc.6601102.

167.Ikeda, K.; Wakimoto, H.; Ichikawa, T.; Jhung, S.; Hochberg, F.H.; Louis, D.N.; Chiocca, E.A. Complement depletion facilitates the infection of multiple brain tumors by an intravascular, replication-conditional herpes simplex virus mutant. J. Virol. 2000, 74, 4765-4775, https://doi.org/10.1128/jvi.74.10.4765-4775.2000.

168.Lun, X.Q.; Jang, J.H.; Tang, N.; Deng, H.; Head, R.; Bell, J.C.; Stojdl, D.F.; Nutt, C.L.; Senger, D.L.; Forsyth, P.A.; McCart, J.A. Efficacy of systemically administered oncolytic vaccinia virotherapy for malignant gliomas is enhanced by combination therapy with rapamycin or cyclophosphamide. Clin. Cancer. Res. 2009, 15, 2777-2788, https://doi.org/10.1158/1078-0432.CCR-08-2342.

169.Segura-Pacheco, B.; Avalos, B.; Rangel, E.; Velazquez, D.; Cabrera, G. HDAC inhibitor valproic acid upregulates CAR in vitro and in vivo. Genet. Vaccines Ther. 2007, 5, 10, https://doi.org/10.1186/1479-05565-10.

170.Lan, Q.; Xia, S.; Wang, Q.; Xu, W.; Huang, H.; Jiang, S.; Lu, L. Development of oncolytic virotherapy: from genetic modification to combination therapy. Front. Med. 2020, 14, 160-184, https://doi.org/10.1007/s11684020-0750-4.

171.Chiu, M.; Armstrong, E.J.L.; Jennings, V.; Foo, S.; Crespo-Rodriguez, E.; Bozhanova, G.; Patin, E.C.; McLaughlin, M.; Mansfield, D.; Baker, G.; Grove, L.; Pedersen, M.; Kyula, J.; Roulstone, V.; Wilkins, A.; McDonald, F.; Harrington, K.; Melcher, A. Combination therapy with oncolytic viruses and immune checkpoint inhibitors. Expert Opin. Biol. Ther. 2020, 20, 635-652, https://doi.org/10.1080/14712598.2020.1729351.

172.Babiker, H.M.; Riaz, I.B.; Husnain, M.; Borad, M.J. Oncolytic virotherapy including Rigvir and standard therapies in malignant melanoma. Oncolytic Virother 2017, 6, 11-18, https://doi.org/10.2147/OV.S100072.

173.Schvartsman, G.; Perez, K.; Flynn, J.E.; Myers, J.N.; Tawbi, H. Safe and effective administration of T-VEC in a patient with heart transplantation and recurrent locally advanced melanoma. J Immunother Cancer 2017, 5, 45-45, https://doi.org/10.1186/s40425-017-0250-5.

174.Le Boeuf, F.; Selman, M.; Son, H.H.; Bergeron, A.; Chen, A.; Tsang, J.; Butterwick, D.; Arulanandam, R.; Forbes, N.E.; Tzelepis, F.; Bell, J.C.; Werier, J.; Abdelbary, H.; Diallo, J.S. Oncolytic Maraba Virus MG1 as a Treatment for Sarcoma. Int. J. Cancer 2017, 141, 1257-1264, https://doi.org/10.1002/ijc.30813.

175.Brun, J.; McManus, D.; Lefebvre, C.; Hu, K.; Falls, T.; Atkins, H.; Bell, J.C.; McCart, J.A.; Mahoney, D.; Stojdl, D.F. Identification of genetically modified Maraba virus as an oncolytic rhabdovirus. Mol. Ther. 2010, 18, 1440-1449, https://doi.org/10.1038/mt.2010.103.

176. Aref, S.; Bailey, K.; Fielding, A. Measles to the Rescue: A Review of Oncolytic Measles Virus. Viruses 2016, 8, https://doi.org/10.3390/v8100294.

177.Robinson, S.; Galanis, E. Potential and clinical translation of oncolytic measles viruses. Expert Opin. Biol. Ther. 2017, 17, 353-363, https://doi.org/10.1080/14712598.2017.1288713.

178. Tayeb, S.; Zakay-Rones, Z.; Panet, A. Therapeutic potential of oncolytic Newcastle disease virus: a critical review. Oncolytic Virother 2015, 4, 49-62, https://doi.org/10.2147/OV.S78600.

179.Angelova, A.L.; Geletneky, K.; Nüesch, J.P.; Rommelaere, J. Tumor Selectivity of Oncolytic Parvoviruses: From in vitro and Animal Models to Cancer Patients. Front Bioeng Biotechnol 2015, 3, 55, https://doi.org/10.3389/fbioe.2015.00055.

180.Samson, A.; Bentham, M.J.; Scott, K.; Nuovo, G.; Bloy, A.; Appleton, E.; Adair, R.A.; Dave, R.; PeckhamCooper, A.; Toogood, G.; Nagamori, S.; Coffey, M.; Vile, R.; Harrington, K.; Selby, P.; Errington-Mais, F.; Melcher, A.; Griffin, S. Oncolytic reovirus as a combined antiviral and anti-tumour agent for the treatment of liver cancer. Gut 2018, 67, 562-573, https://doi.org/10.1136/gutjnl-2016-312009.

181. Friedman, A.; Lai, X. Combination therapy for cancer with oncolytic virus and checkpoint inhibitor: A mathematical model. PLoS One 2018, 13, e0192449, https://doi.org/10.1371/journal.pone.0192449.

182. Sharp, D.W.; Lattime, E.C. Recombinant Poxvirus and the Tumor Microenvironment: Oncolysis, Immune Regulation and Immunization. Biomedicines 2016, 4, https://doi.org/10.3390/biomedicines4030019.

183. Melzer, M.K.; Lopez-Martinez, A.; Altomonte, J. Oncolytic Vesicular Stomatitis Virus as a ViroImmunotherapy: Defeating Cancer with a "Hammer" and "Anvil". Biomedicines 2017, 5, 8, https://doi.org/10.3390/biomedicines5010008.

184.Felt, S.A.; Grdzelishvili, V.Z. Recent advances in vesicular stomatitis virus-based oncolytic virotherapy: a 5year update. J. Gen. Virol. 2017, 10.1099/jgv.0.000980, https://doi.org/10.1099/jgv.0.000980. 
185.Kim, E.; Kim, J.-H.; Shin, H.-Y.; Lee, H.; Yang, J.; Kim, J.; Sohn, J.-H.; Kim, H.; Yun, C.-O. Ad-mTERT$\Delta 19$, a Conditional Replication-Competent Adenovirus Driven by the Human Telomerase Promoter, Selectively Replicates in and Elicits Cytopathic Effect in a Cancer Cell-Specific Manner. Hum. Gene Ther. 2003, 14, 1415-1428, https://doi.org/10.1089/104303403769211637.

186.Guo, Z.S.; Lu, B.; Guo, Z.; Giehl, E.; Feist, M.; Dai, E.; Liu, W.; Storkus, W.J.; He, Y.; Liu, Z.; Bartlett, D.L. Vaccinia virus-mediated cancer immunotherapy: cancer vaccines and oncolytics. J Immunother Cancer 2019, 7, 6, https://doi.org/10.1186/s40425-018-0495-7.

187.Wirth, T.; Zender, L.; Schulte, B.; Mundt, B.; Plentz, R.; Rudolph, K.L.; Manns, M.; Kubicka, S.; Kühnel, F. A telomerase-dependent conditionally replicating adenovirus for selective treatment of cancer. Cancer Res. 2003, 63, 3181-3188.

188. Boettcher, A.N.; Usman, A.; Morgans, A.; VanderWeele, D.J.; Sosman, J.; Wu, J.D. Past, Current, and Future of Immunotherapies for Prostate Cancer. Front. Oncol. 2019, 9, 884, https://doi.org/10.3389/fonc.2019.00884.

189. Martin, N.T.; Bell, J.C. Oncolytic Virus Combination Therapy: Killing One Bird with Two Stones. Mol. Ther. 2018, 26, 1414-1422, https://doi.org/10.1016/j.ymthe.2018.04.001.

190. Schirrmacher, V. From chemotherapy to biological therapy: A review of novel concepts to reduce the side effects of systemic cancer treatment. Int. J. Oncol. 2019, 54, 407-419.

191. Chaurasiya, S.; Fong, Y. Viroimmunotherapy for breast cancer: promises, problems and future directions. Cancer Gene Ther. 2020, 10.1038/s41417-020-00265-6, https://doi.org/10.1038/s41417-020-00265-6.

192.Filley, A.C.; Dey, M. Immune System, Friend or Foe of Oncolytic Virotherapy? Front. Oncol. 2017, 7, 106106, https://doi.org/10.3389/fonc.2017.00106.

193.Lee, C.L.; Veeramani, S.; Molouki, A.; Lim, S.H.E.; Thomas, W.; Chia, S.L.; Yusoff, K. Virotherapy: Current Trends and Future Prospects for Treatment of Colon and Rectal Malignancies. Cancer Invest. 2019, 37, 393414, https://doi.org/10.1080/07357907.2019.1660887.

194.Sborov, D.W.; Nuovo, G.J.; Stiff, A.; Mace, T.; Lesinski, G.B.; Benson, D.M.; Efebera, Y.A.; Rosko, A.E.; Pichiorri, F.; Grever, M.R.; Hofmeister, C.C. A phase I trial of single-agent reolysin in patients with relapsed multiple myeloma. Clin. Cancer. Res. 2014, 20, 5946-5955, https://doi.org/10.1158/1078-0432.CCR-141404.

195.Ady, J.W.; Heffner, J.; Klein, E.; Fong, Y. Oncolytic viral therapy for pancreatic cancer: current research and future directions. Oncolytic Virother 2014, 3, 35-46, https://doi.org/10.2147/OV.S53858.

196. Orchard-Webb, D. Future Directions in Pancreatic Cancer Therapy. JOP: Journal of the pancreas 2015, 16, 249-255, https://doi.org/10.6092/1590-8577/2991

197.Cai, Z.; Lv, H.; Cao, W.; Zhou, C.; Liu, Q.; Li, H.; Zhou, F. Targeting strategies of adenovirus-mediated gene therapy and virotherapy for prostate cancer (Review). Mol. Med. Report. 2017, 16, 6443-6458, https://doi.org/10.3892/mmr.2017.7487.

198. Binz, E.; Lauer, U.M. Chemovirotherapy: combining chemotherapeutic treatment with oncolytic virotherapy. Oncolytic Virother 2015, 4, 39-48, https://doi.org/10.2147/OV.S54780.

199. Cody, J.J.; Hurst, D.R. Promising oncolytic agents for metastatic breast cancer treatment. Oncolytic Virother 2015, 4, 63-73, https://doi.org/10.2147/OV.S63045.

200.Friedman, G.K.; Cassady, K.A.; Beierle, E.A.; Markert, J.M.; Gillespie, G.Y. Targeting pediatric cancer stem cells with oncolytic virotherapy. Pediatr. Res. 2012, 71, 500-510, https://doi.org/10.1038/pr.2011.58.

201.Raja, J.; Ludwig, J.M.; Gettinger, S.N.; Schalper, K.A.; Kim, H.S. Oncolytic virus immunotherapy: future prospects for oncology. J Immunother Cancer 2018, 6, 140, https://doi.org/10.1186/s40425-018-0458-z. 